\title{
An Assessment of the Marine Mammal Abundance and Population Density within the Ghanaian Offshore Construction Areas
}

\section{Anthony Djaba Sackey1, Patrick Ofori-Danson², Benjamin Lantei Lamptey³, Richmond Kennedy Quarcoo ${ }^{4}$}

\author{
${ }^{1}$ Faculty of Earth and Life Science, Selinus University of Science, Bologna, Italy \\ ${ }^{2}$ Department of Marine Science, University of Ghana, Legon, Ghana \\ ${ }^{3}$ Faculty of Earth and Environment, University of Leeds, Leeds, UK \\ ${ }^{4}$ Plastic Punch NGO, Accra, Ghana \\ Email: deckcadetsackey09@gmail.com
}

How to cite this paper: Sackey, A.D., OforiDanson, P., Lamptey, B.L. and Quarcoo, R.K. (2021) An Assessment of the Marine Mammal Abundance and Population Density within the Ghanaian Offshore Construction Areas. Open Journal of Ecology, 11, 758-789.

https://doi.org/10.4236/oje.2021.1111047

Received: March 5, 2021

Accepted: November 7, 2021

Published: November 10, 2021

Copyright $\odot 2021$ by author(s) and Scientific Research Publishing Inc. This work is licensed under the Creative Commons Attribution-NonCommercial International License (CC BY-NC 4.0). http://creativecommons.org/licenses/by-nc/4.0/ (c) (i) (3) Open Access

\begin{abstract}
The Gulf of Guinea region enjoined with the unique characteristics of the Guinea surface and underwater currents driving the upwelling season, besets the ecological importance of the area amidst growing offshore development. Though several attempts are being made to identify the various cetacean species inhabiting the area, little to no progress is made to under the animal population, their behaviour and distribution in the face of the growing threat. The study hence attempts to develop cetacean population and distribution estimation within Ghana's offshore construction sites in the time frame of field development while emphasizing the effects of operations on animal behaviour and habitats, purpose at providing an understanding with the general behaviour of these mammals peculiar to the area and too what level the impact of change is having on distribution trends. The study finds the upwelling tends to suggest, strong animal presence in the area during feeding. Short-fin pilot whales were a dominant cetacean feature within the observed cetacean population estimated to have $160(C V=0.3728)$ presence. Findings suggest the strong biological importance, BIA (habitat, feeding and breeding), as well as operations drawing on animal curiosity, heightened animal vulnerability. Further studies are required to understand the temporal and spatial distributions patterns, while efforts are needed to ensure protected areas are established, animal surveillance and conservative attitudes are encouraged.
\end{abstract}

\section{Keywords}

Marine Cetaceans, Population Density and Abundance, Distance Sampling, Gulf of Guinea 


\section{Introduction}

Marine biodiversity is increasingly an important subject area to the marine scientists who perceive their sustenance as consequential to human existence. Inland, coastal and marine waters underlining the world's oceans, rivers and lakes, all serve to ensure biodiversity regardless of the increasing anthropogenic concerns. Understanding the nature of biodiversity has remained the subject of research survey undertakings. The interest pool spanned species' behaviour, migration patterns, population size, trends, as well as their spatial and seasonal distributions across the ocean.

The west coast of Africa is not exempted from the rising inquisition interest, according to [1]. Reference [2] also suggested the mammalian ecological significance of Ghana's coast waters has only in recent times gained prominence among scientists in a bid to explain the unknown history and lacking data on animal abundance and density estimates. For this study, marine mammals, particularly the small and large cetaceans and their habitation found within the Ghanaian water component of the Gulf of Guinea at remote offshore oil and gas locations are the centres of focus.

Rhetorically, how much is known and documented on Cetaceans in the Area? According to [3], compared to the entire West African sub-region, there are modest levels of information concerning cetacean biodiversity in Northwest Africa (NWA), primarily derived from incidental stranding, sighting accounts and of much recent limited direct monitoring of stranding and by-catches [4] [5] [6]. The assertion is also true for the entire coast of West Africa [7]. Reference [7] asserts that, based on obtained data through vessel-based surveys-sponsored by Japan, as in [8], have provided distributional insights.

Again, from several geophysical seismic surveys that remain buried in unpublished internal reports, among others, like the incomplete record in the CCLME (Canary Current Large Marine Ecosystem) region, as in [7]. These suggest that a simple observer effort from platforms-of-opportunity vessels significantly, contributes to the understanding of the marine mammal biodiversity; and their spatial and seasonal distribution in the Region [3]. Reference [9] proceeded to provide an inventory list of eighteen (18) cetaceans' specimens evident in Ghana. Undertakings of this nature are particularly, important considering the current developmental changes being witnessed within the marine and coastal environment across the world at large. Getting to understand the general behaviour of these mammals peculiar to these areas will help in assessing the impact of the level of changes.

This study, therefore, will attempt to address the following questions directed at the issue. Questions such as; what cetacean species are identifiable to the region? What is the population estimate of these animals found within offshore construction fields at a point in time? Are they evenly distributed thus spatially and seasonally? What are some of the observed behaviours per their interaction with operations offshore? Are there any observed vulnerabilities in the region? 
What are these risks, and how are they mitigated?

Animal density estimations in West Africa are particularly now of essence in other to understand how these animals are lured into construction sites. Thus, riding on the back of Platform-of-Opportunity (PO) vessels for direct sightings, the focus of this study was further narrowed to areas offshore within periods of massive subsea construction operation undertakings.

Offshore marine and subsea operations increasingly have become a feature within the marine and coastal areas of the Gulf of Guinea, whereas Ghana's deep-sea oil and gas development is a recent development example in the Area. This region, found along the equator belt of the South Atlantic Ocean has therefore seen growth in not only traditional commercial shipping routes. It traffics in and out of the various national port facilities in West Africa, but also an expansion to newer offshore zones within the EEZ (Exclusive Economic Zone), new transit routes and rampant vessel traffics from offshore-to-port bases. This spike is in tandem with every new exploratory discovery undergoing development and production. Ghana's growing examples of activities from the Jubilee, TEN (Tweeneboa Enyenra Ntomme) and Sankofa Gye Nyame oil and gas fields after 2010, 2015 and 2017 respectively helps interested parties envisage the potential spikes with every possible discovery in the region across nations with regards to; rise in traffic upon commencement of development towards oil production, future developments among subsequent discoveries, and further or redevelopment of producing fields.

Suffice to add; it is essential to recognize that the coastline waters stretching from shore into deeper waters, thus beyond the continental shelf down the continental slope and towards the ocean floor, is home to the many unique marine species including the cetaceans. The areas of their dwelling have become the subject of a geological query in an economic bid for hydrocarbon resources.

To this effect, surrounding marine environments and living resources within, have had to bear the brand of the destructive changes to their ecological dwellings, migration patterns, food-chain, and social interactions. With limited data forming the level of knowledge about the living mammals in the Area, little to nothing done is fully to protect the endangered species among them.

The study when concluded significantly will provide a deeper understanding of the cetacean population and distribution by developing animal estimation within Ghana's offshore construction sites in the time frame of field development while emphasizing the effects of these operations on behaviours of marine mammals and habitats. Again, the information generated thus in providing a better understanding of marine mammal population within offshore construction fields will help in further assessments across the West African sub-region in support of conservation efforts, while developing the economic relationship between environmental sustenance and potential destruction. In other words, answers to these questions will fill the gap of knowledge relevant to seeking a perfect balance in offshore operations, ecosystem sustenance and the conservation of marine mammal life forms. 


\section{Materials and Method}

\subsection{Study Area}

The study is centrally focusing on offshore deep-water enclaves of Ghana as in Figure 1. It provides a typical outlook into the much recent continuous changes within the marine environment forming part of the habitable zone of marine mammals, thus particularly of the cetacean family.

Ghana, as a growing oil and gas producing country, does boast of several proven identified oil reservoir blocks. These mostly are found in the western sedimentary basin off her west coast. The west coast commences from the east maritime boundary of Ivory Coast and stretches more than halfway [10] again, from her east maritime boundary with Togo. This water resource, as one of the single most important natural asset found within the maritime boundaries of Ghana, is not peculiar to her alone, as neighbouring countries also within the Gulf of Guinea, have made similar significant discoveries.

These discoveries fundamentally go to suggest the gulf of guinea, as one characterized by general unique oceanographic, geographical, geological and atmospheric conditions-one which cuts across the region's nation-states bounded to her north regardless of national borders. They also went ahead to list; the guinea surface and underwater currents, the zones of coastal upwelling and presence of warmth (with high-pressure gradient), and the low levels of salinity in waters as some of the common oceanographic phenomena.

Reference [10] proceeded to establish that offshore construction operation carefully is orchestrated with these unique conditions in mind. The conditions may also very well inform the behaviour and interactions of living mammals found in the region. The study conducted was on the Jubilee Field (See Figure 1) [straddling DWT, (Deep Water Tano) and WCTP, (West Cape Three Point) blocks], near the TEN [within DWT] fields and Sankofa Gye Nyame fields [within OCTP, (Offshore Cape Three Point block)], respectively.

\subsection{Methodology}

The study sites which encapsulate current oil and gas production fields in Ghana's offshore industry examined were during the time frame of field redevelopment, thus before first oil and gas offtakes, and at periods of field maintenance,

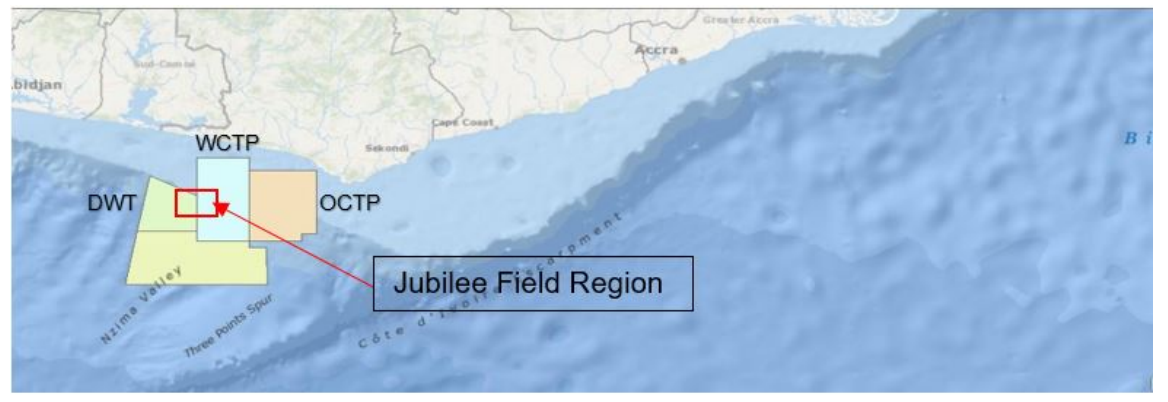

Figure 1. Study interest within the various producing oil and gas blocks offshore Ghana. 
and again, where further or redevelopments projects eminently were pursued. These time frames expected were to show high levels of anthropogenic activities via marine vessel and machinery operations, which underlines the growing changes exerted in the marine environment and the mammal habitation by external forces. The study followed a case study approach while being explorative-thus, combining qualitative and quantitative data gathering and analysis techniques. The approach was aimed at applying a modelling technique in describing the marine mammal population phenomenon on construction fields thus, insofar as simulating the consequence of the marine and subsea operations towards a modelled response towards environmental sustenance and animal conservation.

Data analysis achieved was in three stages with the use of various statistics and geostatistical tool, that is: 1) Geographical data obtained were put through Geospatial analysis and projected to provide visualization of outcomes. The tools utilized in this exercise included ArcGIS 10.8 Software; 2) Statistical estimation of population densities evolved from the use of point transect distance methods via Distance Software version 7.3 on quantitative data gathered, and thus, driving assumptions and nature test to perform in the analysis. Other supporting tools in this regard are Microsoft excel, $\mathrm{R}$ and python statistical environments; 3) The use of comparative arguments was optimized to evaluate qualitative data supporting the observed, consequences.

\section{Data Sources and Analysis}

\subsection{Survey Design}

The areas shown in Figure 2, were examined following the ecological distance sampling methods used in population studies [11] [12]. Given that, activities on offshore construction fields are periodic over limited sea scope and achieved mainly with vessel virtually in stationary positions, thus under dynamic positioning operation. Ultimately, it accounts for longer hours of a vessel restricted in ability to manoeuvre, and relatively the dead-slow speed of vessels.

The Jubilee study site under observation captured in Figure 2 is subsequently stratified into Jubilee (Jub) Strat-A and Jubilee Strat-B for easy sampling (see supplementary material). The Jub-Strat-A area referred to sea areas surrounding Jubilee subsea oil and gas installations in wells, risers, flowline and subsea manifolds tied to FPSO (Floating Production Storage and Offloading unit), while Jub-Strat-B referred to sea areas surrounding CUM (catenary) Moor Buoy located 1 nautical mile away from FPSO unit. See Figure 3 below, for details.

This phenomenon is particularly, important in the survey design choices for the population estimates within the construction site. Therefore, under the distance method, a point transect design technique for sampling survey was employed during animal sightings -focused on the time frame of subsea construction works to which encounters of these mammals are of concern to operations. The stratification, therefore, made use of the boundary coordinates between the 


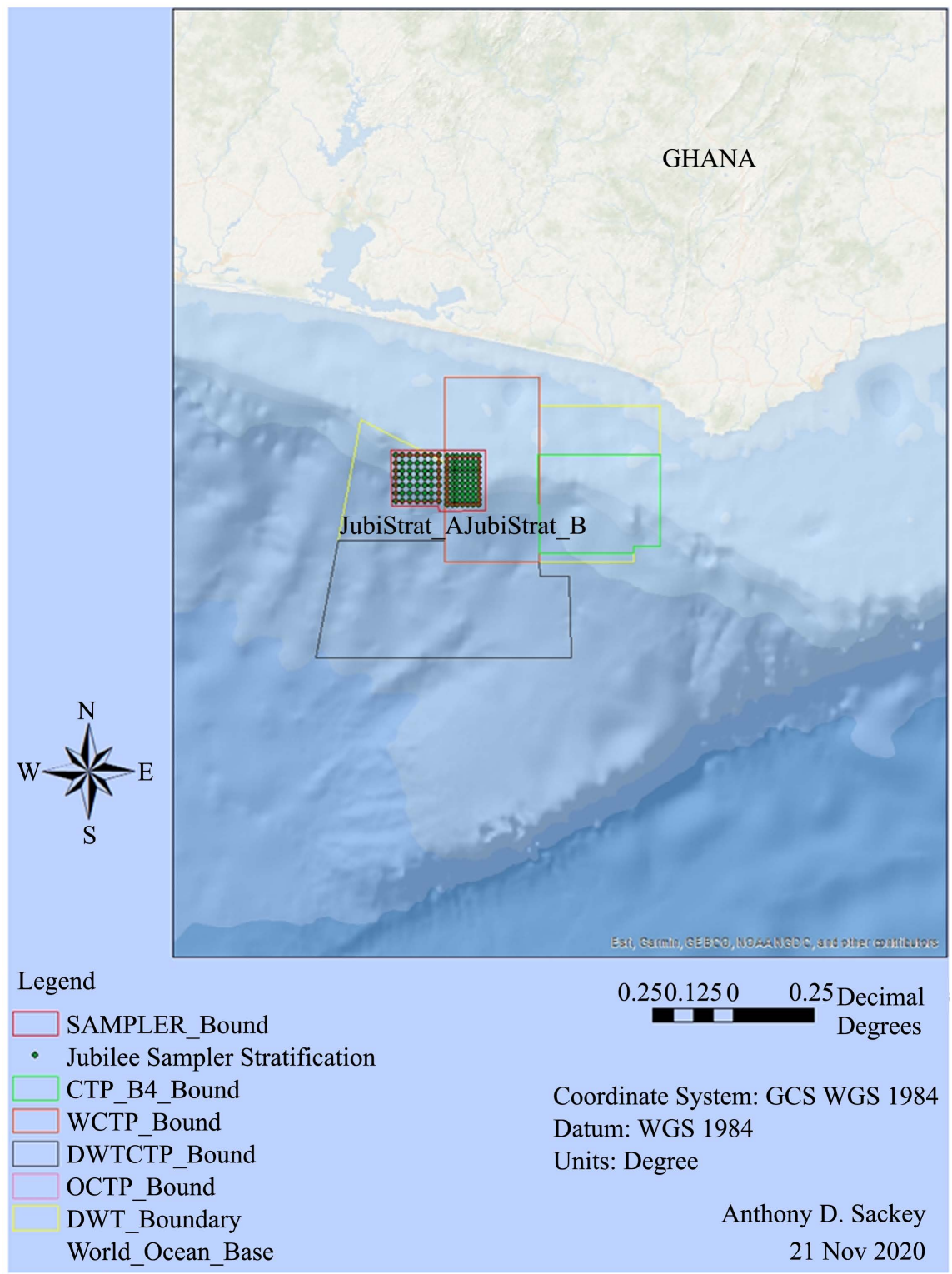

Figure 2. Map of stratified jubilee region for which point transects have been placed.

DWT and WCTP blocks. The approach depicted in Figure 2 and Figure 3, relied on the principle that the animal observed had a random pattern, according to [11].

Due to limited resources and accessibility to the Researchers, the mammal sightings for population estimation focused on the Jubilee field, between January and March, and also September of the year 2020.

The survey areas demarcated are with a single boundary strip having a total coverage area of 521.089 square Kilometres. The individual stratum showed in Figure 3 (also in Figure 2), catered for outliers and the census zone -thus hosting the simple sets of systematic random points generated for the study with the aid of Distance Software version 7.3 and ArcGIS 10.8. One hundred and twenty (120) sampler locations with each sampler having a $1 \mathrm{~km} \times 1 \mathrm{~km}$ grid were 


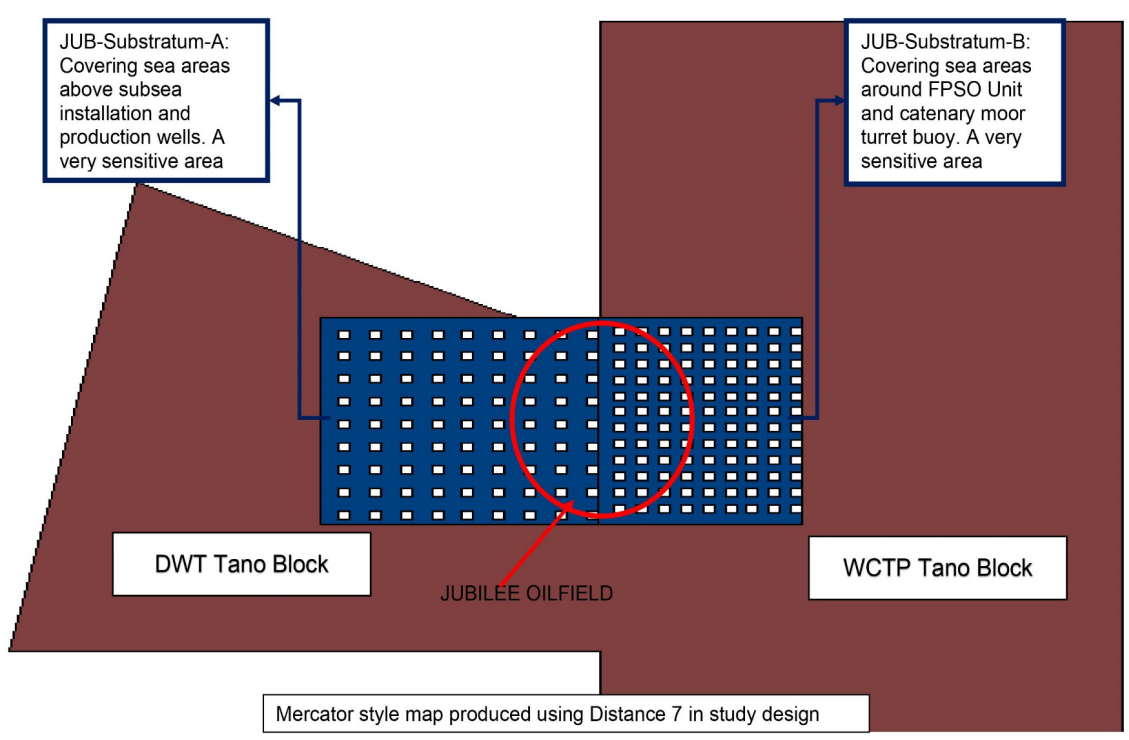

Figure 3. Map depicting deep water Tano \& west cape three point oil and gas blocks of Tullow Ghana Plc. hosting the two study sites containing the sampler points Transect.

placed over the entire study area. The one hundred twenty (120) sampler points developed for animal sighting locations had a 500 meter imaginary radius equivalent to the 500-meter zone specified by United Nations Convention on Law of the Seas, UNCLOS 82 (article 60) requirement around installations. The two stratum targeted animal observer efforts of 45 and 55 per cent in substratum-A and $-\mathrm{B}$ respectively (See Figure 3 above).

\subsection{Field Methods}

This encounter was paramount to understanding the perceived changes influencing mammal behaviour in the Area over time. The Point Transect sampling technique was a systematic design and in agreement with the determined PO vessel, MPSV Seven Borealis' position, which was less random. Thus as described by [12] and [13] for sampling, these animals who are naturally expected are to occur randomly showing a surfacing behaviour [14] in the study area in the data gathering process. The systemic sampler points to the study area were to be achieved at random via the dynamic manoeuvres at dead slow speed and positioning of the Platform-of-Opportunity (PO) vessel (shown in Figure 4) on a predetermined location at any particular point in time during subsea construction operations.

Thus, we assumed that all position achieved by the PO vessel was strictly at sampler locations, and this included those recorded vessel positions slightly away from sampler points. The time spent at each point during dynamic positioning, DP manoeuvrings was averagely $4 / 2$ hour period depending on the nature of subsea operations-suitable for the Point Transect Distance method deployed.

In this case, it was an extension from the PO vessel centreline, (thus for Seven Borealis under restricted manoeuvrability during observations). On the field, the 


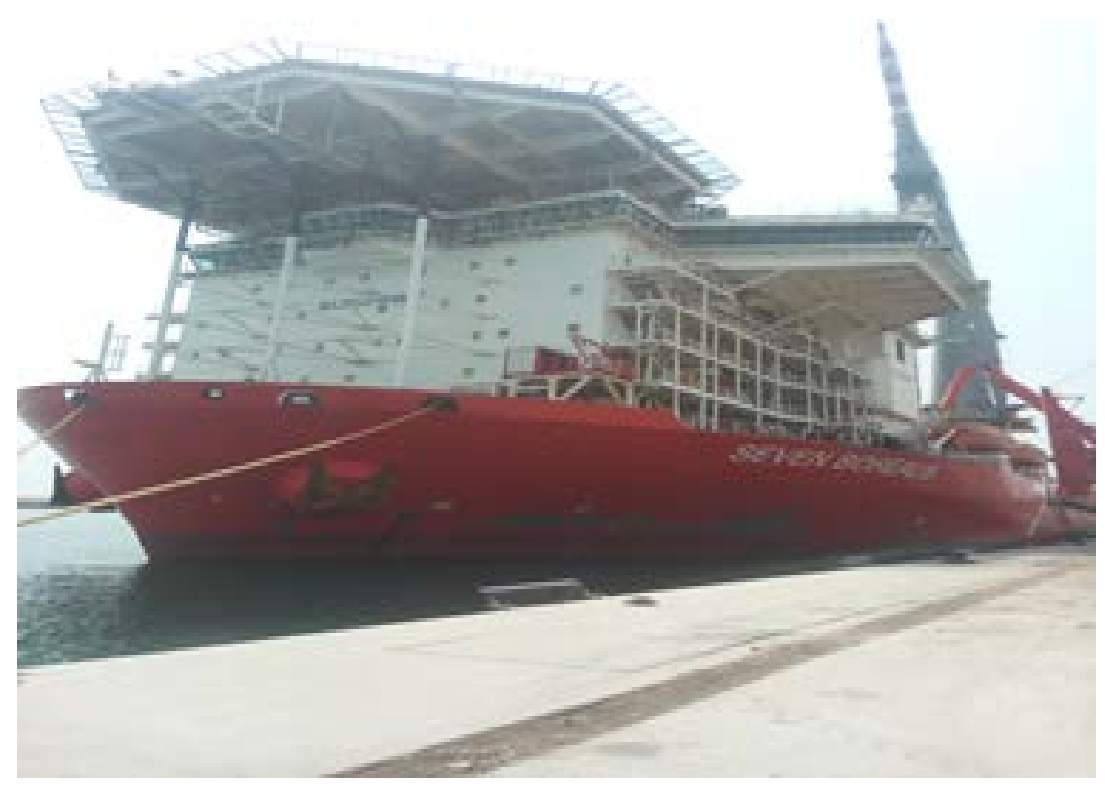

Figure 4. The main platform-of-opportunity PO vessel, Seven Borealis docked alongside new bulk jetty terminal within the Takoradi port.

data gathering process primarily made use of direct (naked) observation, thus "eye" sightings of the animals and only resorted to the handheld marine $10 \times 50$ T Carl Zeiss Binocular (Figure 5) with a suitable focal range beyond $3.3 \mathrm{ft}$ found on the bridge. It helped in identifying the species and features of the animal. Distance estimations were by "eye" per [15] SWFSC marine mammal research ship cruises. Three volunteer observers offered to undertake partial observation to aid the Researcher, though not much emphasis placed was on their effort. Due to the PO vessel's share size, multiple deck layers beside the main deck and the uneven distribution of high rising deck machinery (such as the 5000 metric tonnes crane and J-lay tower) creating blind spots, observers were placed at vintage locations at any given time across the decks. The bridge wings another of observer locations also stood at a height approximately about 46 meters above sea level allowing for a projected view all-round the vessel except in blind spot areas at the stern and starboard side-amidships. Sightings were taken only during the day time between the hours of 0600 gmt and 1800 gmt accounting for 720 minutes per day and 5040 minutes per week depending on the entire duration of study sight.

The observations took into account, the number of animals occurring in clusters or singularly. Also were animal species identification and behaviour. Computational data such as range estimates (taking as the radial distances) and bearing were of animals from the vessel. Other data recorded include weather, time, vessel heading and nature of operations. Primarily, the latter part of data, such as weather records, vessel heading, and position, were obtained from vessel bridge records. Again, through a series of survey interviews with experienced subsea construction personnel aboard (See Table 1), qualitative data obtained to aid in developing the study. 


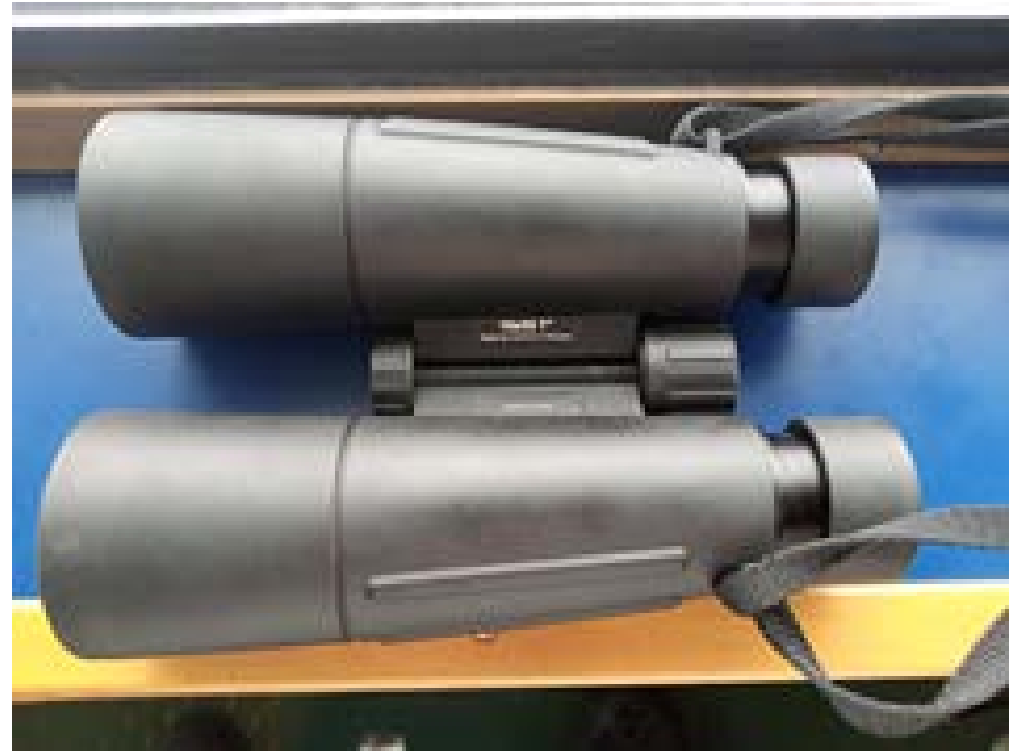

Figure 5. A Carl Zeiss binocular for sightings.

Table 1. Onboard marine vessel resource persons interviewed.

\section{Marine Operation Experts}

1) 7 Borealis Chief Engineer

2) Subsea Surveyor of 7B

3) Project Deck Foreman \& ADFs of 7B

4) Project Engineers of $7 \mathrm{~B}$
5) 7 Adaba Chief Engineer

6) Project Shift Supervisor

7) 7 Borealis Vessel Captain

8) 7 Adaba Electro/Technical Officer (ETO)

9) World Banks Representative Marine Scientists

\subsection{Data Modelling \& Analysis}

The conventional distance sampling method used is the analysis process of the population density and abundance estimation favoured by [16] [17] [18] [19]. They asserted that conventional distance sampling usually adopted hybrid approaches, thus for detection process-by using model-based methods and relying on design-based methods in estimating animal abundance of the study region, whereas estimated probabilities of detection.

The objective of the modelled-based conventional distance sampling deployed was to estimate mean animal density in the Jubilee strata study area based on a survey conducted of animal sightings along with a set of sampler points, distributed in a stratified layer based on a typical systematic random sample design, as in [18]. Essentially, certain assumptions were made before data gathering and during the analysis in regards to sightings, which were of two parts-mainly designed-based thus, 1) Offshore subsea construction works were taking place in fixed locations with floating platforms affixed to the ocean floor at those locations at all times during encounters which occurred randomly. 2) Animals sighted invading these construction sites were residence/inhabitancy of those 
areas at all time and were not moving. These animals were also uniformly distributed across the fields. 3) All observations over the period could not have taken place more than once at any random point. Parameter estimations in this regard cover various extrapolation including; Encounter rate in individual stratum and of the global Region, Detection probability modelled by stratum (and global region), Expected cluster size by stratum (and global region), Density and Abundance by stratum (and global region). Given that several approaches to modelling population abundance estimations proposed over the years are with greater accuracy, this study uses the model described by [19]. The binomial model examines the number of animals' $n$, detected out of a population of $N$ size. It is subsequently multiplied with resulting point transect likelihood, arising from the detection function based on the Conventional Distance Sampling (CDS) survey model.

In summary, the analysis was slightly based mainly on the below theories of estimations concepts by [18] [20] [21], who assumed animal cluster detections were luring as in point transect sightings.

Abundance Estimator: Generally, animal abundance given is by the expression shown below:

$$
\hat{N}=\frac{n A}{2 w L P_{a}}
$$

where in Equation (1) $\hat{N}$ is population estimate, $n$ is the number of observations, and $A$ represents the study area.

Density Estimator: The expression given in Equation (2) below provides animal abundance.

$$
\hat{D}=\frac{n}{2 w L P_{a}}
$$

where $\hat{D}$ is the density estimate; $w$ is the point transect width or radius, and $L$ is the distance between sighting animal and observer.

Equations (1) and (2) therefore can alone be deduced if effective modelling criterion based on the conventional distance point transect sampling design is selected for proper fitness, robustness with limited biasness and variances. Thus are detailed in Section 3.4.1 below.

\subsubsection{Model Selection Criterion and Fitting Test}

Model selection criteria were selected for detection function, global and model fitting requirements. Parameter estimates for data examined on individual stratum under the selection of CDS analysis model were dependent on the likelihood assessment of the critical functions used in delimiting the estimated parameter. Another model fitness test also performed was to evaluate how well it performed on the data. This test included the Chi-sq GOF test. Plot charts, such as plot probability density (pdf) function also used was to evaluate the point transect data thus by superimposing a density curve over radial distances measured. Quantile-quantile, Qq-plot was another graphical evaluation used in 
checking model fitness for the ungrouped data while comparing the distribution of the two variables.

Notwithstanding, the model selection, in general, was achieved using the likelihood assessment statistical estimator described below. The likelihood assessment was essential to understanding the probabilities, $P_{a}$ of observing animals, $n$ over certain distances, $y$. Given that likelihood is denoted by $L_{n, y}$ and expressed as the product of two likelihoods, i.e.

$L_{n}=$ likelihood of obtaining sample size $n, L_{y}=$ likelihood of detections in distances $y$. Thus according to [21], these can be expressed separately as in Equations (3) and (5),

$$
L_{y}=\prod_{i=1}^{n} f_{y}\left(y_{i}\right)=\prod_{i=1}^{n} \frac{g\left(y_{i}\right) \pi_{y}\left(y_{i}\right)}{P_{a}}
$$

Thus given us the likelihood of any animal detection at any distance where $f_{y}(y)$ is the probability density function of distance $y$, the function $g(y)$ is the probability that an animal at a distance $y$ from the point is detected, whereas $\pi_{y}(y)$ : refers to the distribution distances of animals from the point. Thus irrespective of detection or not.

$P_{a}$ is the probability that an animal on the plot is detected, unconditional on its distance $y$. Determining the Probability of detection $P_{a}$ is also given as in Equation (4):

$$
P_{a}=\int_{0}^{w} g(y) \pi_{y}(y) \mathrm{d} y
$$

Thus, a normalizing constant in Equation (5)-ensuring $f_{y}(y)$ remain a valid probability density function. Again, since the plots are randomly placed systematically, can be expressed as; $\pi_{y}(y)=2 y /\left(w^{2}\right)$, Where $w$ is the width of a given point transect. For the sample size model, the natural model used is the binomial distribution likelihood for animals, given as:

$$
L_{n}=\left(\begin{array}{c}
N \\
n
\end{array}\right)\left(\gamma_{c} P_{a}\right)^{n}\left(1-\gamma_{c} P_{a}\right)^{N-n}
$$

where $N$ : is the number of animals in the study region, and $\gamma_{c}$ is the probability of an animal within the study region found is on one of the surveyed plots. Therefore, the overall likelihood formulation as a covariate of Equations (3) and (5) is thus given by [19] as:

$$
\begin{gathered}
L_{n, y}=L_{n} \times L_{y} \\
L_{n, y}=\left(\begin{array}{c}
N \\
n
\end{array}\right)\left(\gamma_{c} P_{a}\right)^{n}\left(1-\gamma_{c} P_{a}\right)^{N-n} \times \prod_{i=1}^{n} \frac{g\left(y_{i}\right) \pi_{y}\left(y_{i}\right)}{P_{a}} \\
L_{n, y}=\left(\begin{array}{c}
N \\
n
\end{array}\right)\left(\gamma_{c}\right)^{n}\left(1-\gamma_{c} P_{a}\right)^{N-n} \prod_{i=1}^{n} g\left(y_{i}\right) \pi_{y}\left(y_{i}\right)
\end{gathered}
$$

The Likelihood Test Performed: A Hazard Rate key function, therefore, was 
deployed in determining the model fitness to empirical distribution function (refer to supplementary material for further analysis).

The Hazard Rate key function given is:

$$
k(y)=1-\exp (-y / A(1))^{\wedge}-A(2)
$$

However, for Jubilee Stratum-A, convergence was not achieved with 14 functional evaluations, having Final $\operatorname{Ln}$ (likelihood) value $=-274.70964$, Akaike Information Criterion, $A I C=553.41931$ and Bayesian Information Criterion, $B I A$ $=556.84644$. Therefore an adjustment with a simple polynomial order of 4, 6 and 8 was implemented in three separate models-all achieving a convergence with 10 (Final $L n$ value $=-258.34734, A I C=522.69470), 174($ Final $L n$ value $=$ $-250.27944, A I C=508.55887$ ) and 35 (Final Ln value $=-227.78479, A I C=$ 465.56958) functional evaluations respectively.

The Likelihood ratio test performed selected the final model with a likelihood ratio test value of 32.7246 based on minimum AIC value.

The same Likelihood assessment conducted in Jubilee stratum-B with Hazard Rate key function (Equation (5)), showed a result of convergence in the first model on 44 functional evaluations with a Final $\operatorname{Ln}$ (likelihood) value = -314.73040 and $A I C$ value of 633.46082 . A second model assessment performed with a simple polynomial adjustment of the order of 4 also achieved convergence with 12 functional evaluations-producing a Final $\operatorname{Ln}$ (likelihood) value = -314.69515 and an AIC of 635.39032. Subsequently, a likelihood ratio test conducted between the two models resulted in a test value of 0.0705 . Therefore, model one implementing hazard rate was selected over model two based on minimal $A I C$ value.

These models implemented were into obtaining the various parameter estimates including; $h(0), p$ and EDR (see Table 2 and refer to supplementary material),

Thus $h(0)=2 \times P I / v, P_{a}$ (or p) probability of observing an object in the defined area and $E D R$ for point transects, effective detection radius $=W \times \operatorname{sqrt}(p)$. Where $v=P I \times W \times W \times p$, is the effective detection area for point transects

Table 2. Results of model selection criterion based on parameter estimates.

\begin{tabular}{|c|c|c|c|c|c|}
\hline Parameter & Point Estimate & Standard Error & Per cent Coef. of Variation & \multicolumn{2}{|c|}{95 Percent Confidence Interval } \\
\hline \multicolumn{6}{|c|}{ Jubilee Stratum-A } \\
\hline$h(0)$ & $0.12026 \mathrm{E}-03$ & $0.68143 \mathrm{E}-04$ & 56.66 & $0.41243 \mathrm{E}-04$ & $0.35066 \mathrm{E}-03$ \\
\hline$p$ & $0.96564 \mathrm{E}-01$ & $0.54716 \mathrm{E}-01$ & 56.66 & $0.33116 \mathrm{E}-01$ & 0.28157 \\
\hline$E D R$ & 128.96 & 36.536 & 28.33 & 73.403 & 226.57 \\
\hline \multicolumn{6}{|c|}{ Jubilee Stratum-B } \\
\hline$h(0)$ & $0.87888 \mathrm{E}-04$ & $0.18425 \mathrm{E}-04$ & 20.96 & $0.57990 \mathrm{E}-04$ & $0.13320 \mathrm{E}-03$ \\
\hline$p$ & 0.13213 & $0.27700 \mathrm{E}-01$ & 20.96 & $0.87182 \mathrm{E}-01$ & 0.20025 \\
\hline$E D R$ & 150.85 & 15.812 & 10.48 & 122.33 & 186.02 \\
\hline
\end{tabular}


CDS Qq-plot: statistically, the CDS fitting test based on the quartile-quartile plot, Qq-plot was conducted to compare the fit of the detection function model to the data by plotting cumulative distribution function ( $c d f)$ against the empirical distribution function ( $e d f)$ for which results of each substratum are given in Figure 6 and Figure 7.

Thus, for $c d f$, the given $F(x)$ results in a probability of distances less than or equal to $x$ for a given model while $S(x)$ results in a proportion of data with distances less than $x$. Hence, $c d f$ fitted for each observation on each stratum shows strong fitness, however, with little spikes along the distribution curve. Therefore, Kolmogorov-Smirnov and Cramer-von Mises goodness of fit tests are used to confirm the Qq-plot results.

\subsubsection{CDS Model Goodness of Fit Test to Be Performed}

Three individual tests were determined as appropriate and run on the model, upon which two main tests were carried out, was on the detection function probability distribution in each survey area. A Kolmogorov-Smirnov ( $K-S$ test $)$ test performed

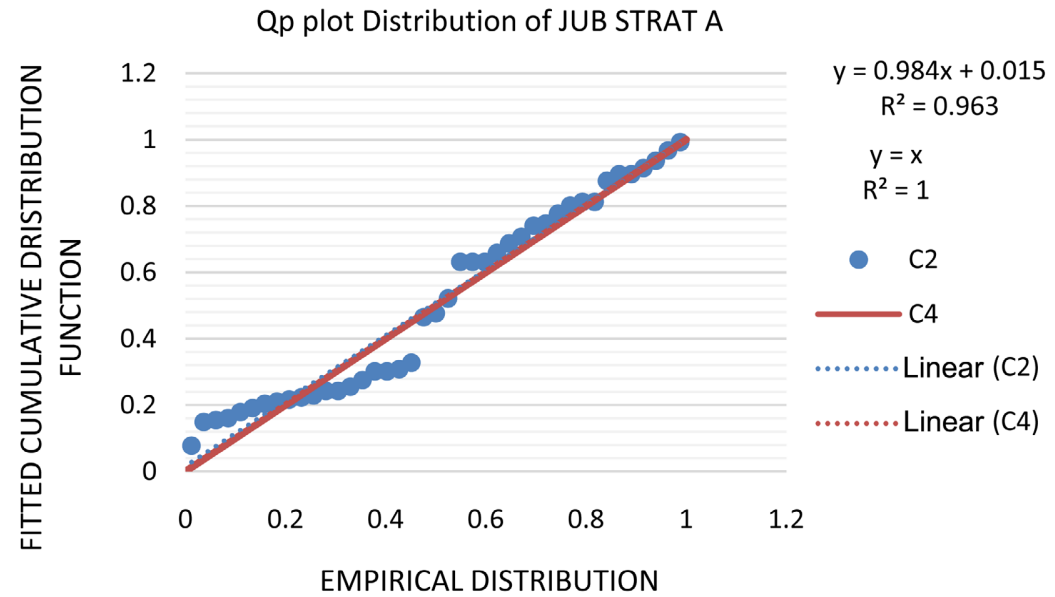

Figure 6. Qq-plot for data distribution over Jubilee Stratum-A region.

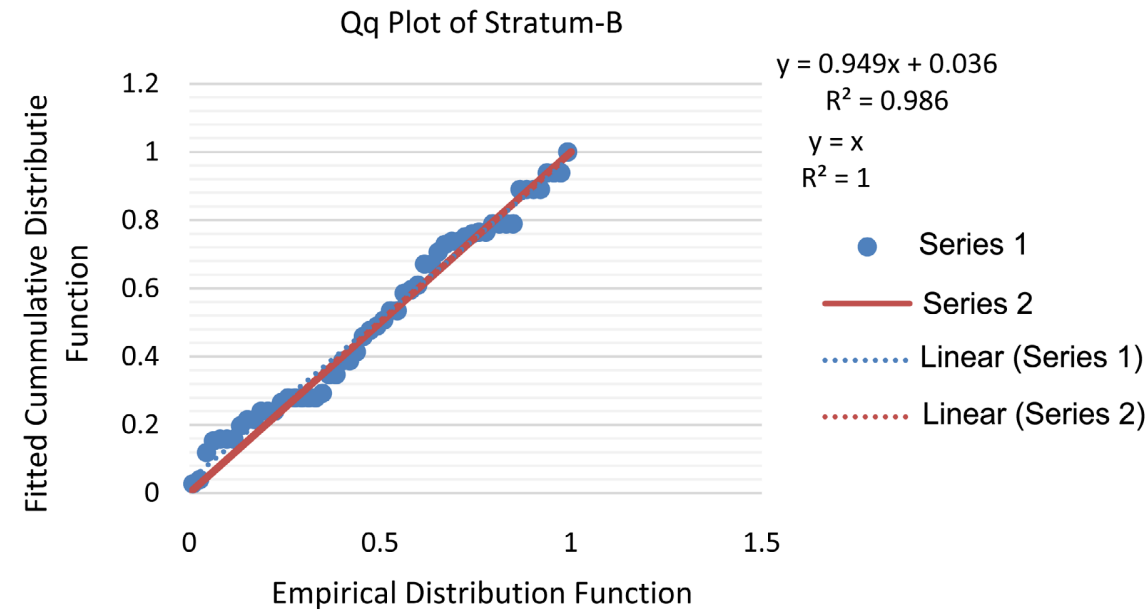

Figure 7. Qq-plot for data distribution over Jubilee Stratum-B region. 
in stratum A and B. The upper tail probability, $p$-value $=0.4385$ in relation to $n$ $=41$ observation, from sighting efforts. The test yielded a cumulative $D n=$ 0.1356. The test indicated a convergence correlation between the cumulative distribution function ( $c d f$ with ascending index $i=1, n, F(x))$ and empirical distribution function ( $e d f, S(x)$ ) smaller difference -showing the goodness of fit.

The same test was performed on stratum B with $n=56$ observation given an upper tail probability, $p$-value $=0.6375$, a Dn-value of 0.0994 -suggesting a strong positive correlation between $c d f$ and edf functions. According to [22] [23], this test performed is suitably accurate in practical applications with sample sizes greater than or equal to 35 . The second test performed was the Cramer-von Mises (Cv-M) family tests that focused on the sum of squared differences between $c d f$ and edf. A Cramer-von Mises test with uniform weighting function also carried out examined the goodness of fit of the probability detection function values evaluated through the relationships,

$$
Q=n \int_{-\infty}^{\infty}[F(x)-S(x)]^{2} \varphi(x) \mathrm{d} F(x)
$$

where $\varphi$ is a weighting function allowing for the weighting of different parts of the distribution.

In given all observations the same weight, a standard $\mathrm{Cv}-\mathrm{M}$ was deduced statistically via.

$$
W^{2}=\frac{1}{12 n}+\sum_{i=1}^{n}\left\lceil\stackrel{m}{F}\left(x_{i}\right)-\frac{i-0.5}{n}\right\rceil
$$

The tail probabilities of $W^{2}$, always relies on sample size (5 - 1000) of a-levels $\left(\alpha_{1}<p<\alpha_{h}\right)$. If simulated bases on the equation, it obtains sets of critical values on the sample size, for $W^{2}$, where $\alpha_{1}$ and $\alpha_{h}$ are the bounding critical values. Again Cramer-von Mises test with cosine weighting function though similar to the above test is performed for observations with distances closer to zero ( 0 distances). In this case, the weighting function utilized is:

$$
\cos \left(\pi x_{i} / 2 w\right)
$$

where $x_{i}$ the radial is the distance of observation, and $w$ is the given truncation distance.

$$
C^{2}=\frac{-16 n}{\pi^{3}}+\frac{2}{\pi} \sum_{i=1}^{n}\left(2 \hat{F}\left(x_{i}\right)-\frac{2 i-1}{n}\right) \sin \left(\frac{\pi}{2} \hat{F}(x)\right)+\frac{4}{\pi} \cos \left(\frac{\pi}{2} \hat{F}\left(x_{i}\right)\right)
$$

Note: tail probability for $C^{2}$ are also calculated and presented the same way as in $W^{2}$. Refer to [23] for further reading on tail probability theory. This test is, as also discussed by $[13]^{1}$, gave the results presented in Table 3 (refer to supplementary material for further analysis).

In summary, the data obtained herewith modelled using Distance Software version 7.3, primarily relying on [12] CDS methods. The probability of detection function was modelled as a function of observed radial distances from sampler points while making use of robust, semi-parametric methods, in randomizing ${ }^{1}$ Further reading on the model employed, refer to [16]. 
Table 3. Confirmation test for model fitness based on Kolmogorov-Smirnov and Cramer-von Mises family tests.

\begin{tabular}{cc}
\hline Jubilee Stratum-A & \multicolumn{1}{c}{ Jubilee Stratum-B } \\
\hline Kolmogorov-Smirnov test & \multicolumn{1}{c}{ Kolmogorov-Smirnov test } \\
D_n $=0.1356 p=0.4385$ & \multicolumn{1}{c}{ D_n $=0.0994 p=0.6375$} \\
Cramer-von Mises family tests & \multicolumn{1}{c}{ Cramer-von Mises family tests } \\
W-sq (uniform weighting) $=0.1314$ & W-sq (uniform weighting) $=0.0790$ \\
$0.400<p \leq 0.500$ & 0.600 $<p \leq 0.700$ \\
Relevant critical values: & Relevant critical values: \\
W-sq crit (alpha $=0.500)=0.1193$ & W-sq crit (alpha $=0.700)=0.0789$ \\
W-sq crit $($ alpha $=0.400)=0.1470$ & W-sq crit $($ alpha $=0.600)=0.0973$ \\
C-sq (cosine weighting) $=0.1091$ & C-sq $($ cosine weighting $)=0.0600$ \\
$0.300<p \leq 0.400$ & 0.600 $<p \leq 0.700$ \\
Relevant critical values: & Relevant critical values: \\
C-sq crit $($ alpha $=0.400)=0.0963$ & C-sq crit $($ alpha $=0.700)=0.0502$ \\
C-sq crit $($ alpha $=0.300)=0.1222$ & C-sq crit $($ alpha $=0.600)=0.0624$ \\
\hline
\end{tabular}

the outcome, where there were repeat counts at specific locations, the temporal correlation initiated by using random-effects as in [24] [25].

\section{Results and Discussions}

The study coinciding with upwelling season in the region, generally took into account time spent on-board Platform-of-Opportunity vessels primarily on the Jubilee field over the 2020 years of study. However, opportunistic sightings on separate occasions within the year 2015 on the TEN field, the year 2017 to 2018 while on the Sankofa Gye Nyame subsea construction projects helped project a better understanding of the offshore marine mammal habitations within the west coast of Ghana. However, when developing the population density estimates and abundance, the study specifically focused on Jubilee Strata, over the last three-month (January-March) time spent by Researchers onboard two marine vessels, namely; MPSV Seven Borealis (central observer platform) and AHST (anchor handling and support tug) Seven ADABA, in a bid to identify and populate marine mammal interactions during the entire duration of the construction project undertaking by Subsea 7 Engineering UK ltd., on behalf of Tullow Ghana Plc and partners. An assessment of observer effort, probability of detection, animal encounter rates, as well as density and abundance were computed. The following are a representation of outcomes.

\subsection{Observer Survey Effort}

As mentioned in earlier paragraphs, the CDS statistical modelling technique implemented, determined the population density and abundance estimation based on fundamental parametric values on data obtained between January and March 2020 over 73 days on the study, Jubilee offshore strata area within the Greater jubilee enclave of Deep Water Tano (DWT) and West Cape3 Point (WCTP) oil 
blocks. The Jubilee strata further divided into the Jubilee Strat-A \& Strat-B saw a slightly varied survey effort respectively per design, with the latter as high as 55 per cent (out of $100 \%$ ) effort rate. Survey efforts spread over 118 out of 120 systematically designed sampler locations visited between January and March 2020. The design percentage effort rate did not account for coverage areas; instead, areas of much direct active subsea installation operations compared to the relatively low activity area. The Jubilee Substratum-A: represented sea areas of $308.765 \mathrm{sq} \cdot$ Kilometres above and surrounding oil and gas wells and subsea installation locations, while the Jubilee Substratum-B: represented sea areas of $212.324 \mathrm{sq} \cdot$ Kilometres beneath and surrounding surface installations of the FPSO Kwame Nkrumah, KNK and the newly installed CUM Turret buoy mooring station (as shown in Figure 2 and Figure 3 in early sections, and Table 4 here).

The biasness in the design skewed towards Jubilee substratum B was essential if we were to develop an understanding of installation operations as one of the luring factors influencing encounter rates, or otherwise. Hence, from Table 4, a total coverage area of $56.88 \mathrm{sq} \cdot \mathrm{Km}$ (representing 10.92 per cent out of 521.089 sq. $\mathrm{km}$ ) received direct survey efforts per observations made within an $E D R$ area to a total of $7.1235 \mathrm{sq} \cdot$ Kilometres. Importantly, understanding the marine environment of the Area of observations made is herewith essential identifying the peculiarities of the habitat hosting the animals of interest and is discussed in the proceeding paragraphs.

\subsection{The Identified Marine Mammals within the Region}

In developing the understanding of the various marine mammal species (particularly, of the cetacean species) identifiable within the region, a review of the limited literature on the topic, was the source forming the basis of the field inquiries and interviews. Generally, the biodiversity of the West African and Macaronesia ocean environments do boast of over one-third of the world's known species on small cetaceans regardless of the unknown conservation status of these animals in contrast to other areas around the world [26] [27]. Reference [26] and [9] asserted the validation of identifiably eighteen (18) different cetacean species (seventeen (17) odontocetes, and one mysticete) found in West Africa subtropic fauna (as in [26]; notwithstanding this known fact, only eleven (11) are listed).

Table 4. Total area covered and surveyed on effort per daytime sightings on the Jubilee strata area.

\begin{tabular}{cccccc}
\hline Study Region & Total coverage Area in & Days on & Survey effort per daytime in & Total Area covered on effort in \\
\cline { 2 - 3 } \cline { 5 - 6 } (Jubilee oil field) & Sq.km & Survey & Km & Hr./min & Sq.km \\
\hline Substratum A & 308.765 & 32 & 24.00 & $348 / 23,040$ & $25.971(2.5078)$ \\
Substratum B & 212.324 & 41 & 35.00 & $492 / 29,520$ & $37.329(5.0042)$ \\
$\begin{array}{c}\text { Total of Plot-A: } \\
\text { Jubilee Strata }\end{array}$ & 521.089 & 73 & 59.00 & $876 / 52,560$ & $56.88(7.5120)$ \\
\hline
\end{tabular}


These identified mammals included; Atlantic [28] [29] humpback dolphin (Souza Tuezii), Long-beaked Common Dolphin (Delphinus Capensis), Harbour Porpoises. The PO vessel departed the port of Takoradi on the 10th of January and arrived at the Jubilee oil field under 12 hours travelling at an average speed of $4.8 \mathrm{kn}$.

Direct field observations aboard PO vessels revealed the well-known fact of the various observable individual marine mammal species within the region. Species identifications were incredibly challenging for species sighted surfacing once at farther distances and in some cases of those sightings generally made at greater distances beyond 350 meters away from the observer. Such subsequently, were classified as "unidentified cetaceans". Relatively, captured videos and pictures of some of these animals that were nearer were subsequently shared with the study's resource persons to confirm these species. Animals were identified based on the various unique features associated with the body form, colour, behaviours and markings where necessary based on internationally acceptable guidelines among other such as that documented by Boucher and Boaz, for the National Marine Laboratory (NML), Northwest \& Alaska Fisheries Center (NAFC), National Marine Fisheries Service (NMFS), the NOAA, and AMMPA standardized information: Bottlenose Dolphin. Table 5 below shows the list of both identified and unidentified but suspected cetaceans howbeit among other animal species recorded over the survey period.

These observed species of animals listed in Table 5 goes to suggest that the Area under study affirms the assertion by [25] [26] of the vibrant biodiversity inherent in the offshore ocean environment of the Gulf of Guinea. The sightings of the study also confirmed the presence of three main cetacean species of the order Odontocetes (i.e., Short-fin pilot whales shown in Figure 8, Bottlenose Dolphins and Atlantic humpback dolphins [29]).

Table 5. Observed species of cetaceans in the marine mammal survey on jubilee construction field.

\begin{tabular}{|c|c|c|c|}
\hline $\begin{array}{l}\text { Period of Observation } \\
\quad \text { (in months) }\end{array}$ & $\begin{array}{l}\text { Length of Tracking } \\
\text { (in Days) }\end{array}$ & $\begin{array}{l}\text { Identified Cetacean Species, } \\
\text { (spp.) }\end{array}$ & $\begin{array}{l}\text { Remarks base on Suspicion } \\
\text { or Possible Specie identity }\end{array}$ \\
\hline Jan & 1 & $\begin{array}{l}\text { Bottlenose Dolphin } \\
\text { (Tursiops truncatus) }\end{array}$ & Identified \& unconfirmed \\
\hline Jan-June-July-Aug & 1 & Unidentified Dolphin & $\begin{array}{c}\text { Suspected Atlantic Humpback } \\
\text { Dolphin (Sousa Teuzii) } \\
\text { unconfirmed }\end{array}$ \\
\hline Jan-Feb-Mar & 59 & $\begin{array}{c}\text { Short-fin Pilot Whales } \\
\text { (Globicephala macrorhynchus) }\end{array}$ & Identified and confirmed \\
\hline Feb & 2 & Shark & Unknown species \\
\hline Mar, Sept & 3 & Sea Turtle & \\
\hline Mar, Sept & 6 & Mantra & $\begin{array}{l}\text { Identified \& Observed } \\
\text { subsea via ROV }\end{array}$ \\
\hline
\end{tabular}




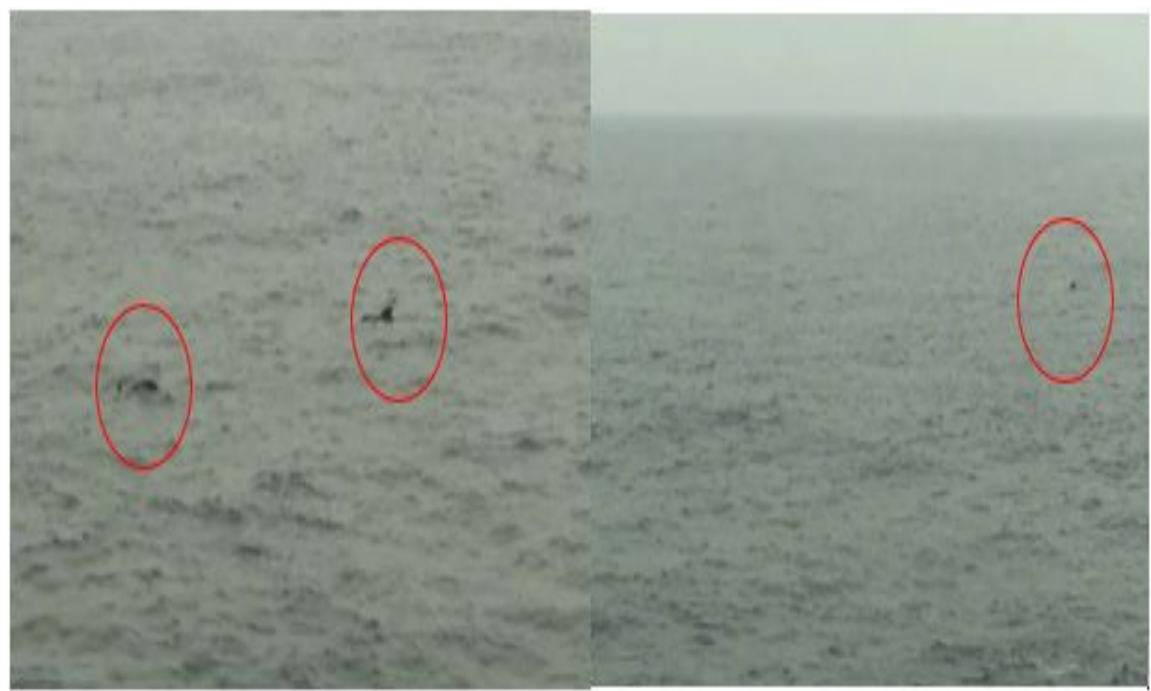

Figure 8. Image short-fin pilot whales captured within the Jubilee oil production field.

The latter dolphins per [29] were unidentified and are only a suspected species per the observed behaviour. The inability to confirm the latter two species was because direct imaging was not possible due to distances sustained between animal and Researcher on PO vessel. Agreeably, though the adjacent field in the DWT block designated in this study (thus the TEN field) could not be studied for mammal estimation. According to [30], in the EIA report, sightings of ten (10) different species of marine animals were recorded with a majority of 43 per cent consisting of dolphins. Reference [30] also asserted that the most commonly identified species was the short-finned pilot whales, which is in agreement with the study's findings.

However, [30] recommended that a dedicated survey by experienced marine scientist to carried out subsequently to present the accurate estimation of marine mammals and turtle species of the Area. The other study site thus of the Sankofa Gye Nyame fields did not cover animal estimation at this time, however, had no information on marine mammals within the field as in [31]. To better understand the extent of the biodiversity, a population density and abundance estimation subsequently, is carried out on both identified and unidentified cetacean species within the Jubilee field. These detailed results are, as shown in the following paragraphs.

\subsection{The Jubilee Field Animal Population Density and Abundance Estimations}

The survey efforts on the entire jubilee strata were biased towards Jubilee Substratum B which was seeing the direct offshore installation operations compared to the adjacent substratum A, thus having $45 \%$ search effort committed to Jubilee Substratum-A and a 55\% effort rate to Jubilee substratum-B. This effort did account for the various encounter rates observed during the survey even though some survey locations were visited more than twice. 


\subsubsection{Animal Encounter Rates}

Estimation of animal encounter rate was particularly critical in determining the animal abundance and cluster sizes since the animals encountered were mostly in groups spread over undetermined distances per every survey location, (sampler points, $k=118$ out of 120 designed samplers). Table 6 below presents the details of the encounter rate estimates per survey efforts.

In total, 97.000 animals $(n)$ encounters were of cetaceans belonging to the order Odonteces (thus predominantly of Globicephala macrorhynchus spp.) over the period for the offshore shipboard survey area. These findings, correlated with findings by [32]; suggesting Globicephala macrorhynchus were widely distributed across the world's ocean within tropical waters to warm temperate waters. 56 animal encounters out of the total sum observations, were made within the Jubilee Substratum-B coverage area at 35 survey point locations-projecting an encounter rate $(n / K)$ of $0.16000 E-02(C V=0.0602$ certainty). Subsequently, an encounter rate of $0.17083 E-02$-determined regards, $n=41$ animals encountered within Jubilee Substratum-A at 24 (out of 48) sampler locations. In summary, the rates of the encounter on both strata were fairly even regardless of the uneven distribution of survey efforts-and thus suggesting a slight variance in animals' detection probability, $P_{a}$ estimates.

\subsubsection{Estimating the Probability of Detection, $P_{a}$}

Animal encounter rates were dependent on the detectability of animals, given that some animals may not have been detected. From the histograms of frequency and radial distances seen in Figure 9 of animal sightings, $P_{a}$ is estimated of the area above the probability detection function curve (i.e. assuming everything

Table 6. Encounter rates within substratum of the jubilee oil field study area.

\begin{tabular}{|c|c|c|c|c|c|c|}
\hline $\begin{array}{l}\text { Stratum } \\
\text { Name }\end{array}$ & $\begin{array}{c}\text { Survey } \\
\text { parameters }\end{array}$ & $\begin{array}{l}\text { Estimated } \\
\text { Value }\end{array}$ & $\% \mathrm{CV}$ & $\operatorname{deg} . f$ & @ 95\% Confi & lence Interval \\
\hline \multirow{6}{*}{ Substratum A } & $\mathrm{n}$ & 41.000 & \multirow{6}{*}{6.96} & \multirow{6}{*}{47.00} & \multirow{6}{*}{$0.14853 \mathrm{E}-02$} & \multirow{6}{*}{$0.19649 \mathrm{E}-02$} \\
\hline & $\mathrm{k}$ & 48.000 & & & & \\
\hline & $\mathrm{K}$ & 24000 . & & & & \\
\hline & $\mathrm{n} / \mathrm{K}$ & $0.17083 \mathrm{E}-02$ & & & & \\
\hline & Left & 0.0000 & & & & \\
\hline & Width & 415.00 & & & & \\
\hline \multirow{6}{*}{ Substratum B } & $\mathrm{n}$ & 56.000 & \multirow{6}{*}{6.02} & \multirow{6}{*}{69.00} & \multirow{6}{*}{$0.14191 \mathrm{E}-02$} & \multirow{6}{*}{$0.18039 \mathrm{E}-02$} \\
\hline & $\mathrm{k}$ & 70.000 & & & & \\
\hline & $\mathrm{K}$ & 35000 . & & & & \\
\hline & $\mathrm{n} / \mathrm{K}$ & $0.16000 \mathrm{E}-02$ & & & & \\
\hline & Left & 0.0000 & & & & \\
\hline & Width & 415.00 & & & & \\
\hline
\end{tabular}




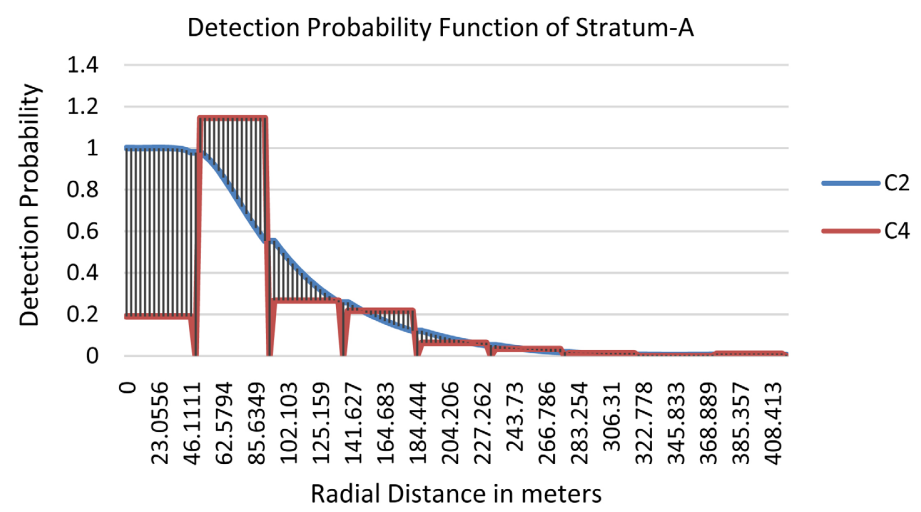

Figure 9. Depicts statistical graphs of; area sustained between the probability function three superimposed on the histogram of radial distances measured for Jubilee Substratum-A.

is seen at zero distance) to the area under the curve, where the area above the curve indicates the animals estimated to that have been missed. Figure 9 and Figure 10 shows $P_{a}$ to Radial distances for both Jubilee substratum-A and -B respectively.

For substratum-A, the Probability of detection, $p$ was estimated at $0.96564 \mathrm{E}-01$ (while relying on as high as five parameters, $(\mathrm{m}=5)$ to improve fitness with minimal high variance) - projecting high levels of detectability ranging over a $95 \%$ confidence interval of $0.33116 \mathrm{E}-01$ to 0.28157 , based on Akaike information criterion $(A I C=465.57)$ value (See Figure 9 above).

This value demonstrates that more animals are in areas under Effective Detection Radius distances (where EDR $=128.96$ meters, 95\% C.I of 73.403 meter < $E D R<226.57$ meter), upon encounter on survey effort while also suggesting that more were less likely to be detected at longer EDR distances on a 95\% confidence interval. The p-value had a high $C V=0.5666$ indicating reduced certainty in detectability of animals in the Area.

In Jubilee substratum-B (with an estimate of $p=0.13213$ ), a probability of detection, $\mathrm{p}$ derived based on three-parameter $(\mathrm{m}=2)$ was selected for model fitness (shape criterion and robustness), which is a relative sense that had an $A I C$ value of 633.46 , suggesting minimal variance and biasedness compared to stratum $\mathrm{A}$, hence, the less $C V$ value $(C V=0.2096)$.

Given a $95 \%$ confidence interval of $\mathrm{p}$ at $0.87182 \mathrm{E}-01$ and 0.20025 , animal detectability upon encounter under areas of Effective Detection Radius, $(E D R=$ 150.36 meter) was relatively high at farther EDR distance not exceeding 186.02 meters (See Figure 10). In other words, observed detectability rate $\mathrm{p}$ of 0.13213 for example, short-fin pilot whales sighted within the study subregion stratum-B were more likely to be detected along farther $E D R$ distances approaching between 122.33 meters and 186.02 meters to a $95 \%$ confidence interval compared to, $p$ of $0.96564 E-01$ approaching distances of 73.403 meters and 226.57 meters within Jubilee Substratum A study locations. Conclusively, the above-discussed conditions give a 95\% confidence level in the data obtained for animal detectability except for the slight uncertainty shown in Jubilee substratum-A study area. 




Figure 10. Depicts statistical graphs of; Area sustained between the probability function three superimposed on the histogram of radial distances measured for Jubilee Substratum-B.

This observation is with no regard to any other unquantifiable factors of uncertainties introduced, during survey effort reshaping outcomes. The animal detection conditions are an influence on the density and abundance estimates derived from the survey data.

\subsubsection{Animal Distribution, Density and Abundance Assessment}

Given that, the total animal population of the entire Gulf of Guinea generally, remains unknown for both identified and unidentified cetacean spp., some have suggested, lack of interest and high cost involved in carrying out such a task over the years, as being the predicate delaying these common scientific queries. An encounter with a marine scientist on a World Bank-funded marine mammal survey in 2017 while onboard LCV Polar Onyx Bergen within offshore OCTP Ghana, buttressed this assertion-explaining the limitations and suggesting a national consciousness following determined effort is required to make headway. It is in light of this, the population of marine animals in the Jubilee oil field construction area is examined. In developing an understanding of the spatial distribution of the animals studied in the region, concerns focused on both temporal and seasonal distributions. However, due to the coronavirus outbreak becoming a global pandemic in mid-march 2020, construction projects on the jubilee field were subsequently halted and suspended to a later date, therefore, this phase of the study could not proceed any further. The limited data is therefore used to project an understanding of the animal distribution to the time frame observed (seasonal patterns). Researchers, therefore, are planning further studies in the nearest future to provide a global understanding of the spatial and seasonal patterns within the Gulf of Guinea region.

\subsubsection{Trends of Animals Occurrence}

The model estimates design to cater for animals occurring singularly and in clusters to delimit population abundance or densities. An average cluster size of 17.950 (with hazard rate adjustment estimate as 19.712, and 95\% C.I of 15.537 and 25.009), determined for animals observed within Jubilee substratum-A ( $C V$ 
$=0.1002$ ) with a $95 \%$ confidence interval range along 14.666 and 21.970 . Jubilee substratum-B, however, had the shared animal cluster size observation of 8.9643 $(C V=0.1198)$ over a 95\% confidence interval ranging between 7.0575 and 11.386 animal cluster sizes. These cluster sizes are depicted in the regression plots shown in Figure 11 and Figure 12 for each stratum, respectively.

\subsubsection{Animal Density and Abundance}

Of the small cetacean spp., observed from delineated strata of the specified study period, animal density cluster size, density and abundance are given in Table 7.



Figure 11. Regression plot chart depicting cluster size distribution within Jubilee substratum-A.

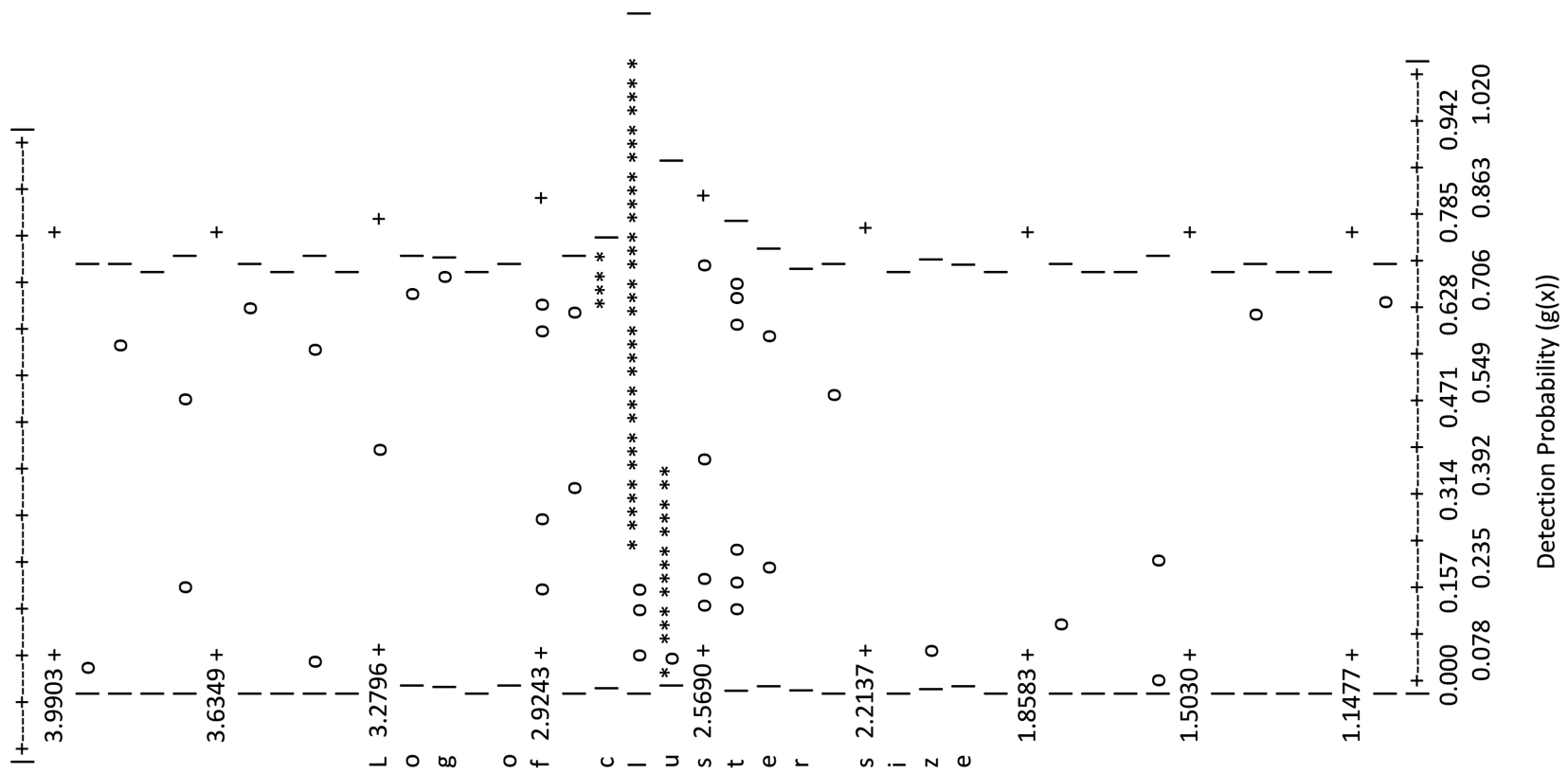

Figure 12. Regression chart depicting cluster size distribution within Jubilee substratum-B. 
Table 7. Density and abundance estimates within Jubilee offshore oil construction strata.

\begin{tabular}{ccccccc}
\hline Stratum Name & Density \& Abundance parameters & Estimated Value & \% CV & Deg. F & @ 95\% Confidence Interval \\
\hline & DS & $0.16349 \mathrm{E}-01$ & 57.09 & 37.09 & $0.55737 \mathrm{E}-02$ & $0.47954 \mathrm{E}-01$ \\
Substratum: A & $\mathrm{D}$ & 0.32226 & 58.30 & 40.25 & 0.10803 & 0.96132 \\
& $\mathrm{~N}$ & 100.00 & 58.30 & 40.25 & 33.000 & 297.00 \\
\hline & $\mathrm{DS}$ & $0.11190 \mathrm{E}-01$ & 21.81 & 62.94 & $0.72734 \mathrm{E}-02$ & $0.17216 \mathrm{E}-01$ \\
Substratum: B & $\mathrm{D}$ & 0.28601 & 23.52 & 82.51 & 0.18029 & 0.45374 \\
& $\mathrm{~N}$ & 61.000 & 23.52 & 82.51 & 38.000 & 96.000 \\
\hline $\begin{array}{c}\text { Entire offshore } \\
\text { Jubilee Strata } \\
\text { study area }\end{array}$ & $\mathrm{DS}$ & $0.14247 \mathrm{E}-01$ & 39.44 & 39.50 & $0.66044 \mathrm{E}-02$ & $0.30733 \mathrm{E}-01$ \\
& $\mathrm{D}$ & 0.30749 & 37.28 & 45.20 & 0.14870 & 0.63586 \\
\hline
\end{tabular}

From Table 7 above, one observes that for animals occurring in clusters, their observed mean population cluster per sea area coverage was $0.14247 \mathrm{E}-01$ cluster size per sq. kilometres. However, the overall animal density estimated for the 104 $(C V=0.3728)$ population of animals observed was $0.30749(C V=0.3728)$ animal per sq. $\mathrm{km}$. In conclusion, this estimate goes to suggest that animal abundance within the offshore construction sites averaged at 33.67 per cent, which is slightly above one-third of the mean population observed. This data overall is not a comprehensive estimate on the entire offshore constructions fields in Ghana and the Researchers herewith recommend further studies in this regard.

\subsection{Observed Animal Interactive Behaviour with Operations}

Animals were observed for established associated behaviours well documented. However, the focus was had on curious intrusive interactive behaviour on the field as this had a direct impact on the life-threatening risk they may face during operations. Two observed scenarios illustrate this behaviour demonstrated in the field. These state as follows:

1) The animal approach of installations or vessels: animals showed a sense of curiosity though it remains unclear to what level their movement towards installations or vessels was influenced by the abnormally occurring in their natural habitable zones. Operations naturally were without the radiated noises, structural and machinery movements through water columns, general navigation and effect of nighttime lighting. This behaviour suggests some level of intrusive behaviour in the animals that is worth investigating within offshore construction sites.

2) Animal cycling of installations or vessels: again animals were observed cycling platforms before continuing in their path. This observed behaviour was not peculiar to single individuals of animals observe but the animal in small cluster sizes of individuals. The phenomenon observed suggests a curious behaviour on the part of the animals that need to be studied in other to understand 
how animals interact with a changing habitation.

In concluding, it is unclear, however, as to whether the behavioural actions observed amounted to animals' pursuit of feed source, a natural intrusive behaviour or just out of curious expeditions. One or two or all may apply to these animals and therefore, the need for further studies. Thus, if there are any behavioural changes in the marine animals, we can easily assess how much is attributable to, for example, vibration noise stressors. Reference [33] in their study' Exposure to Seismic Survey Alters Blue Whale Acoustic Communication', illustrated for example that blue whales changed their calling behaviour in response to relatively low source-level sounds from the seismic survey, and thus calling more during periods without seismic noise.

\subsection{Observed Vulnerabilities and Possible Mitigations}

From the observed behaviours of animals on site, several questions were asked on subsea construction engineers and marine experts as to why this was the case virtually throughout the entire duration of the operation and whether they deemed these situations as projecting some form of vulnerability on the animals in the region. Respondents affirmed that these were apparent vulnerabilities observed, especially when animals out intrusive curiosity came very close to subsea assets, platforms and vessels in the field. As to whether such concerns have been fatal for any of these animals, they were confident it rarely happens in the industry, as most were yet to encounter such incidence in their offshore work experience. In a related incident, two respondents, however, recounted an incidence where they observed within several meters of water-depth from ROV cameras, a shark hitting on the subsea ROV. According to the respondents, the sight was frightening yet intriguing to observers watching through helpless through the lenses of Subsea Seven 7 Borealis ROV subsea survey cameras. As to what might have contributed to this situation, one can identify the intense lighting around the ROV. Another reason is the noise as well as the wake or washes from ROV thrusters. With this said, Respondents, affirmed by extension the vulnerability of the observed animals. They suggested operations naturally took every necessary caution like momentarily stopping ROV operations to mitigate such threat posed to the endangered mammals or animals. Respondents subsequently identified general navigation, DP manoeuvring, subsea machinery and infrastructural movement, pollution especially of plastic, and oil spillage as a possible lifethreatening risk for animals when in the oil field. Respondents were however of the belief, plastic debris was relatively dangerous due to the time it took to decompose if mistakenly ingested. Hence, the large number of poly planks accompanying subsea assets after being used in operations among other pollutants are disposed of under strict environmental management policy by these subsea engineering companies.

However, observations over the years gave clear indications some of these broken plankings, ends up in the open sea. The 2020 field study, in effect, per- 
mitted the observation of operations of nine active marine vessels (seen in Figure 13 below), engaged in the field, with each serving as a multiplying factor of the level of danger (subject to the variously identified element risk aggregations) sustained for a set period of project development.

These are shown in Table 8. These were vessels with unique capabilities and strength in terms of engine horsepower, machinery and tonnages.

Table 8. List of vessels and installations sighted and the risk they posed.

\begin{tabular}{|c|c|c|c|}
\hline Vessel Type & $\begin{array}{l}\text { Nature of Operations and } \\
\text { Identified Risk Elements }\end{array}$ & $\begin{array}{l}\text { Risk } \\
\text { Count }\end{array}$ & Mitigation \\
\hline $\begin{array}{l}\text { Heavylift and } \\
\text { Pipelay vessel }\end{array}$ & $\begin{array}{l}\text { Subsea construction works such as pipeline } \\
\text { production and heavy lift installations } \\
\text {-risk factor (Noise, collision during Navigation/DP } \\
\text { manoeuvring, Subsea Machinery and structure } \\
\text { movement, ROV, Pollution) }\end{array}$ & 6 & $\begin{array}{l}\text { Design, planning (e.g. speed, no. of } \\
\text { active engines), Enforcement } \\
\text { \& monitoring, Reporting, } \\
\text { Contingency response }\end{array}$ \\
\hline $\begin{array}{l}\text { Anchor Handling } \\
\text { and piling vessel }\end{array}$ & $\begin{array}{l}\text { Subsea installations work such as installation anchors } \\
\text { by piling } \\
\text {-risk factor (Noise, collision during Navigation/DP } \\
\text { manoeuvring, Subsea Machinery, Pollution and ROV) }\end{array}$ & 5 & $\begin{array}{l}\text { Design, planning, Enforcement } \\
\text { \& monitoring, Reporting, } \\
\text { Contingency response }\end{array}$ \\
\hline $\begin{array}{c}\text { Offshore } \\
\text { Support vessel }\end{array}$ & $\begin{array}{l}\text { Providing tow, security, bunkering and } \\
\text { logistical support. } \\
\text {-risk factor (Noise, collision during } \\
\text { Navigation/DP manoeuvring, and tow structure } \\
\text { movement, and pollution) }\end{array}$ & 4 & $\begin{array}{l}\text { Design, planning, Enforcement } \\
\text { \& monitoring, Reporting, } \\
\text { Contingency response }\end{array}$ \\
\hline $\begin{array}{l}\text { Offshore support } \\
\& \text { rescue vessel }\end{array}$ & $\begin{array}{l}\text { Providing towing support for the offtake shuttle tankers } \\
\text {-risk factor (Noise, collision during Navigation/DP } \\
\text { manoeuvring, and pollution) }\end{array}$ & 3 & $\begin{array}{l}\text { Design, planning, Enforcement } \\
\text { \& monitoring, Reporting, } \\
\text { Contingency response }\end{array}$ \\
\hline MODU & $\begin{array}{l}\text { Engaged in drilling operations } \\
\text {-risk factor (Noise, collision during Navigation/DP } \\
\text { manoeuvring, Subsea Machinery movement, } \\
\text { ROV and pollution) }\end{array}$ & 5 & $\begin{array}{l}\text { Design, planning, Enforcement } \\
\text { \& monitoring, Reporting, } \\
\text { Contingency response }\end{array}$ \\
\hline FPSO & $\begin{array}{l}\text { Serves as oil production and storage platform } \\
\text {-risk factor (Noise and Pollution) }\end{array}$ & 2 & $\begin{array}{l}\text { Design, planning, Enforcement } \\
\text { \& monitoring, Reporting, } \\
\text { Contingency response }\end{array}$ \\
\hline OSV & $\begin{array}{l}\text { Providing tow, security, and logistical support } \\
\text {-risk factor (Noise, collision during } \\
\text { Navigation/DP manoeuvring, and pollution) }\end{array}$ & 3 & $\begin{array}{l}\text { Design, planning, Enforcement } \\
\text { \& monitoring, Reporting, } \\
\text { Contingency response }\end{array}$ \\
\hline support tug & $\begin{array}{l}\text { Providing security and rescue logistical support } \\
\text {-risk factor (Noise, collision during navigation, } \\
\text { and pollution) }\end{array}$ & 3 & $\begin{array}{l}\text { Design, planning, Enforcement } \\
\text { \& monitoring, Reporting, } \\
\text { Contingency response }\end{array}$ \\
\hline $\begin{array}{l}\text { Accommodation } \\
\text { barge }\end{array}$ & $\begin{array}{l}\text { Providing floating hotel accommodation and } \\
\text { logistical support } \\
\text {-risk factor (Noise, collision during } \\
\text { Navigation/DP manoeuvring, and pollution) }\end{array}$ & 3 & $\begin{array}{l}\text { Design, planning, Enforcement } \\
\text { \& monitoring, Reporting, } \\
\text { Contingency response }\end{array}$ \\
\hline $\begin{array}{l}\text { CUM Turret Buoy. } \\
\text { Not under } \\
\text { command installation }\end{array}$ & $\begin{array}{l}\text { Serves as turret offloading mooring unit for } \\
\text { loading tankers } \\
\text {-risking (Pollution) }\end{array}$ & 1 & $\begin{array}{l}\text { Design, planning, Enforcement } \\
\text { \& monitoring, Reporting, } \\
\text { Contingency response }\end{array}$ \\
\hline
\end{tabular}




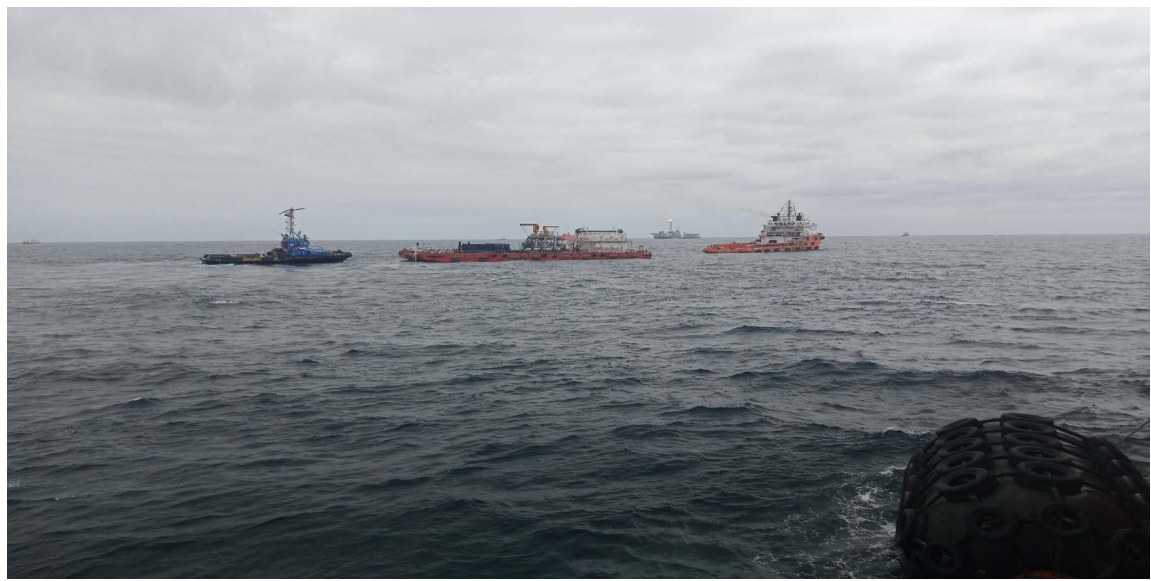

Figure 13. Several specialised offshore marine vessels actively engaged in construction. Activities appear to pose a danger to both marine life and LFBs.

As listed in Table 8, as observed in the field, these vessels by operation posed life-threatening concerns for these animals. There were also other concerns referred to by the consulting scientists. About addressing the lack of state-sponsored mammal monitoring and surveillance, the respondent decried the situation and asserted that there is a need for urgent attention in addressing the situation. Respondent believed the current state of affairs did not demonstrate a commitment to marine mammal conservation.

Hitherto, the respondent referred to a rise in dolphin harvesting as a growing challenge amongst local artisanal fisher folks, which needed redress by the state. It is unclear if these are generally incidental by-catch or deliberate dolphin harvesting. Currently, scientist relies mostly on local informants within the fishing communities for information as a result of the limited resources allocated to monitoring. Through this approach, a non-governmental body, thus Ghana wildlife society recently obtained a video of a harvested common bottlenose dolphin (Tursiops truncatus) onboard a local fishing boat (LFB) being mishandled by the crew at one of the landing beaches along Ghana's western coast.

Relatively, the problem highlighted by the non-governmental institution, Ghana wildlife society reflects on the lack of deterrent measures, surveillance and monitoring by state institutions to the unregulated presence of these LFBs in the waters (see Figure 14) which are also a frequent future within offshore operational sites in the exclusive economic zone, EEZ as described in [10]. Their operations influence the marine mammal's population trends [1] within the region.

In a rare moment while on the Sankofa Gye Nyame oil field the year 2017, the Researchers were occasioned to have observed an unidentified whale (i.e. animal length approx.. 8 and 12 meters precisely the size of most of the LFBs with outboard motors) tracking the movement of an LFB on its course within proximity of roughly 20 - 30 meters. Intriguingly, at every turn of the LFB as it navigated the field, the whale followed making the same turn. Perhaps, this could be interpreted as the whale had mistaken the fishing boat for a fellow whale or animal of social interest. The situational concern also does project the vulnerability of the 


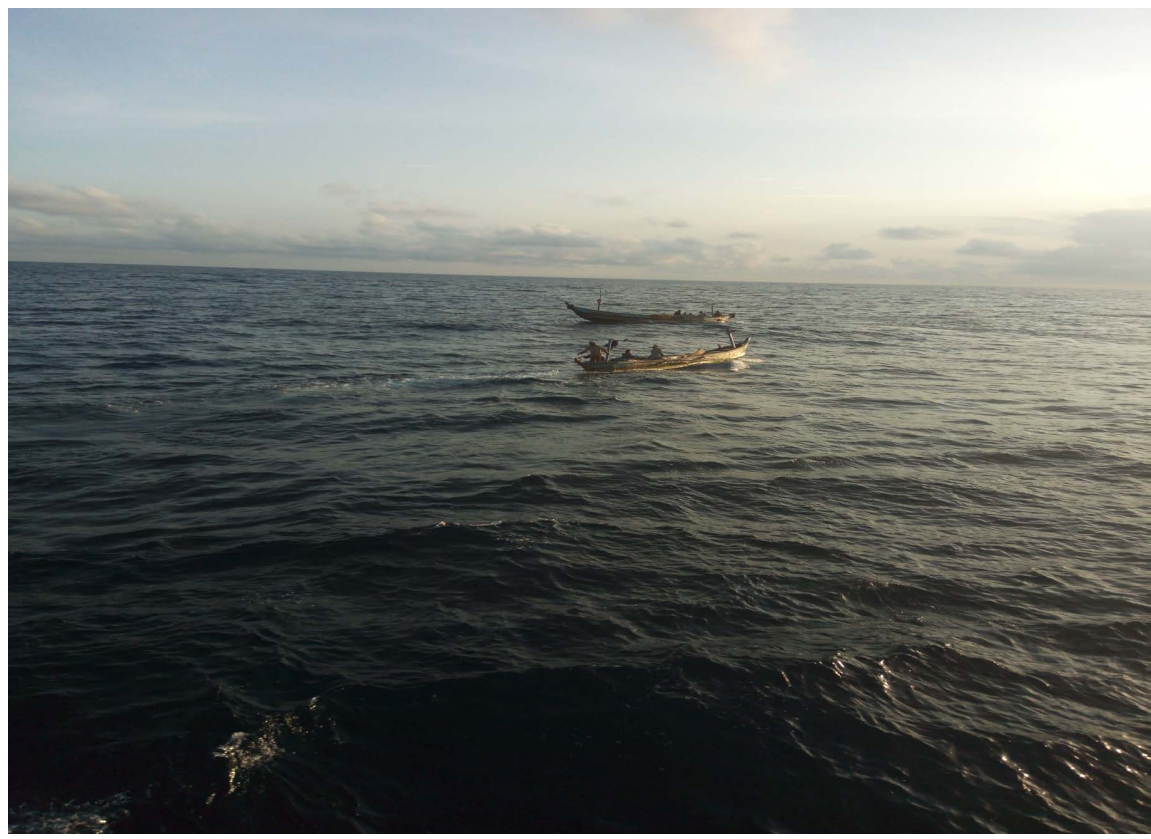

Figure 14. LFB fitted with outboard motor frequently sighted traversing within 50 meters of construction vessel on the Offshore Sankofa Gye Nyame field. This behaviour flouts international and local regulations (i.e. 500 meter zone requirement).

animals in light of both large and small marine vessels operated (see Figure 13 and Figure 14) among other environmental and safety concerns posed by LFBs highlighted by [10]. On the issue of sponsored surveillance, the expert marine respondent commended the World Bank Group for making regular mammal monitoring on the Sankofa Gye Nyame oil field a prioritized requirement in the financial arrangement with the offshore operator, ENI and partners. This arrangement though was to ensure the oil-producing company the World Bank-financed fully met the initial Ghana EPA EIA requirement on mammal species survey prior to the field development; this at least ensured continuous regular monitoring of the animals throughout the development and a bit into the life span of oil-producing period. The issue of regular monitoring is, however, not the case generally, for oil fields in Ghana and Africa since operations in 2010. Again, on the concerns of vulnerability, expert respondents and others continue to call for the creation of a marine sanctuary zone. Respondents believe it will help limit encroachment on the marine mammal habitation while providing a haven for their survival, procreation and feeding.

\section{Summary, Conclusion and Recommendation}

\subsection{Summary}

The study surveyed cetacean populations within the offshore Jubilee oil field construction site to develop an understanding of the population of animals in the Area and how they interacted with construction operations. The study sort expert opinions on relevant concerns and undertook and shipboard survey within January to March, and September when due to covid-19 health crises and 
restriction concerns, the study proceeded to an abrupt end amidst the suspension of the pipeline production project by seven Borealis. Overall weather was good, with an irregular pattern of rainfalls occurring at various points in time.

The average Visibility was 6 to 8 nautical mile, allowing observers to carry out sighting watches within areas of the designed sampler radial distances. Virtually, all sighting occurred during the day with fewer mention of night time sightings which discussed concerns of nocturnal animal behaviour.

In summary, the animal population abundance at $160.00(C V=0.3728)$ animals with an estimated density of $0.30749(C V=0.3728)$ over the entire study region (see Table 7). An average cluster size of 17.950 and 23.482 was observed within respective status-projecting a pooled cluster density of $0.14247 \mathrm{E}-01$. Animals (Figure 8) showed a curious and intrusive behaviour on the field coming in at close as within 36 meters from construction (PO) vessel while cycling vessel for a period before moving on. Vessel operators were aware of the situations and to mitigating measures to the best of their abilities, where they deem the danger posed was inevitable. Where the state's mandate was of concern, it notes the little progress made, thus with no long-term biodiversity conservation policy for these living marine mammals.

\subsection{Conclusion}

The study's findings have highlighted several concerns within the marine environment with considerable challenges as offshore operations continue to expand in the Gulf of Guinea of West and Central Africa. The area naturally is beset with rich marine and coastal eco biodiversity (attested to with the recent discovery of deepwater coral reefs in the area) that require some protection and development. Again, the Cape3 Point enclave (see Figure 1) suggests the possible presence of coral reefs along the stretch of the west coast due to the long term effects of wind and ocean current dynamics of the area. Researchers suggest some of these coral reefs are identified but remain unexplored. This is largely because marine wildlife conservatory monitoring has not been prioritised in Africa regardless of the economic benefits, the local economies stand to gain (e.g. tourism). Ghana's situation is no different in this regard. Anthropogenic activities near the coast and offshore therefore risk the destruction of these biodiversities if no proper and stringent effort is put in place to ensure its sustenance. The situation also does have health implications for human life and animals in general. It concludes by alluding to the single fact that environmental safety is only expensive and properly value only after the fact of an incident had occurred. Going by this approach with the "wait and see" attitude in environmental governance is not a sound and prudent management practice anywhere in the world. These animals (in Figure 8) have economic benefit in terms of tourism if properly managed, especially during the breeding season and winter season when migratory species, join in regional and local breeds of cetaceans as they deck nearshore and along the coast. After these findings, the study, therefore, concludes by making a few recommendations. 




Figure 15. Model of Integrated actionable approach at ensuring marine animal conservation and environmental sustenance.

\subsection{Recommendations}

The recommendations listed here are directed at developing a model for an integrated approach towards marine conservations and ecological sustenance focused on key stakeholders (see Figure 15) such as: policymakers, financial stakeholders, field operators, NGOs, academia and researchers, as well as the local fishing community in the maritime industry making use of the area.

The integrated recommended actions should be directed at ensuring:

1) An expressed requirement for stationed observers' onboard marine vessel during all phases of the oil development cycle and into production life of offshore oil and gas fields are made in any form of agreement by the coastal state authorities.

2) The strengthening and enforcement of marine mammal conservation efforts by education, penalizing defaulters and designating certain sea areas as protected areas, PA.

3) Financial stakeholders are obliged to ensure surveillance and reporting as part of an investment mandate.

4) Academic institutions, NGOs and researchers among others through a consented effort, expand interest in marine conservation issues while drawing attention to the potential crises.

5) Local fishers are to be discouraged from direct or otherwise "by-catch" harvesting of marine mammals to be used as bait for shark harvesting at sea. 


\section{Acknowledgements}

The authors wish to acknowledge the marine environmental action group, the Plastic Punch Organisation for sponsoring the dissemination of findings with the publication of this very study.

The authors wish to acknowledge all personnel involved and for the support received from Subsea 7 UK especially, the crew of LCV Polar Onyx, MPSV Seven Borealis and Adaba Teams during the Tullow Jubilee Turret Remediation project. We also wish to thank the reviewer, Prof Fava Salvatore and Selinus University, where this study formed part of the corresponding author's Ph.D. thesis. Overall appreciation goes to God almighty for making the occasion possible.

\section{Conflicts of Interest}

The authors declare no conflicts of interest regarding the publication of this paper.

\section{References}

[1] Van Waerebeek, K., Uwagbae, M., Segniagbeto, G., Bamy, I.L. and Ayissi, I. (2015) New Records of Atlantic Humpback Dolphin in Guinea, Nigeria, Cameroon and Togo Underscore Fisheries Pressure and Generalized Marine Bushmeat Demand. BioRxiv035337. https://doi.org/10.1101/035337

[2] Tullow Ghana Limited-Environmental Resource Management (TGL/ERM) (2009) Environmental Impact Assessment: Jubilee-Field-Eia-Chapter-4-pt2. https://www.tullowoil.com/download_file/view/604/

[3] Valdés, L. and Déniz-González, I. (2015) Oceanographic and Biological Features in the Canary Current Large Marine Ecosystem. IOC Technical Series, IOC-UNESCO, Paris, $383 \mathrm{p}$.

https://aquadocs.org/bitstream/handle/1834/9135/233299E.pdf?sequence=1\&isAllo wed $=\mathrm{y}$

[4] Hazevoet, C.J., Monteiro, V., López, P., Varo, N., Torda, G., Berrow, S. and Gravanita, B. (2010) Recent Data on Whales and Dolphins (Mammalia: Cetacea) from the Cape Verde Islands, Including Records of Four Taxa New to the Archipelago. Zoologia Caboverdiana, 1, 75-99.

https://islandlab.uac.pt/fotos/publicacoes/publicacoes_Hazevoet10_Recentdatawhal esdolphinsMammaliaCetaceaCapeVerde.pdf

[5] Perrin, W.F. and Van Waerebeek, K. (2012) The Small-Cetacean Fauna of the West Coast of Africa and Macaronesia: Diversity and Distribution. Western African Talks on Cetaceans and Their Habitats, Adeje, 16-20 October 2007, 12 p. https://www.researchgate.net/publication/263273867_The_small-cetacean_fauna_of _the_west_coast_of_Africa_and_Macaronesia_diversity_and_distribution

[6] Mullié, W.C., Wagne, M.M., Elmamy, C.A.A., Yahya, F.M., Veen, J. and Van Waerebeek, K. (2013) Large Number of Stranded Harbour Porpoises phocoena as By-Catch Victims in Mauritania. Scientific Committee-International Whaling Commission, Jeju Island, 3-15 June 2013, 5 p.

[7] Van Waerebeek, K., Debrah, J.S. and Ofori-Danson, P.K. (2014) Cetacean Landings at the Fisheries Port of Dixcove, Ghana in 2013-14: A Preliminary Appraisal. International Whaling Commission Scientific Committee Annual Meeting, Bled, 12-24 May 2014, 4 p. 
[8] Sohou, Z., Dossou-Bodjrenou, J., Tchibozo, S., Chabi-Yaouré, F., Sinsin, B. and Van Waerebeek, K. (2013) Biodiversity and Status of Cetaceans in Benin, West Africa: An Initial Assessment. West African Journal of Applied Ecology, 21, 121-134. https://www.ajol.info/index.php/wajae/article/download/94736/84105

[9] Van Waerebeek, K., Ofori-Danson, P.K. and Debrah, J. (2009) The Cetaceans of Ghana: A Validated Faunal Checklist. West African Journal of Applied Ecology, 15, 61-90. https://doi.org/10.4314/wajae.v15i1.49428 https://www.researchgate.net/publication/215705744_The_Cetaceans_of_Ghana_a_ Validated_Faunal_Checklist/references

[10] Sackey, A.D. and Lamptey, B.L. (2019) Activities of Local Fishermen within Ghana's Offshore Construction Fields, Impact on Operations- "Polar Onyx" Experience. Regional Maritime University Journal, 6, 85-102. http://www.ajol.info/index.php/rmuj

[11] Krebs, C.J. (2017) Chapter 5, Estimating Abundance: Line Transects and Distance Methods. In: Krebs, C.J., Boutin, S. and Boonstra, R., eds., Ecological Methodology, Benjamin Cummings, San Francisco, 198-230. https://www.zoology.ubc.ca/ krebs/downloads/krebs_chapter_05_2017.pdf

[12] Buckland, S.T., Anderson, D.R., Burnham, K.P., Laake, J.L., Borchers, D.L. and Thomas, L. (2001) Introduction to Distance Sampling: Estimating Abundance of Biological Populations. Oxford University Press, Oxford.

[13] Villano, M. (2007) The Deepest Divers: D-Tags Give Scientists In-Depth Records of Whales in the Depths. The Woods Hole Oceanographic Institution. https://www.whoi.edu/oceanus/feature/the-deepest-divers/

[14] Taylor, B. (2014) SWFSC Marine Mammal Survey, SWAPS 1997, Cruise 1607. http://seamap.env.duke.edu/dataset/1028

[15] Fewster, R.M. and Buckland, S.T. (2004) Assessment of Distance Sampling Estimators. In: Buckland, S.T., Anderson, D.R., Burnham, K.P., Laake, J.L., Borchers, D.L. and Thomas, L., Eds., Advanced Distance Sampling, Oxford University Press, Oxford, 281-306.

[16] Buckland, S.T., Oedekoven, C.S. and Borchers, D.L. (2016) Model-Based Distance Sampling. Journal of Agricultural, Biological, and Environmental Statistics, 21, 58-75. https://doi.org/10.1007/s13253-015-0220-7

[17] Borchers, D.L., Stevenson, B.C., Kidney, D., Thomas, L. and Marques, T.A. (2015) A Unifying Model for Capture-Recapture and Distance Sampling Surveys of Wildlife Populations. Journal of the American Statistical Association, 110, 195-204. https://doi.org/10.1080/01621459.2014.893884

[18] Borchers, D.L., Buckland, S.T. and Zucchini, W. (2002) Estimating Animal Abundance: Closed Populations. Springer, London. https://doi.org/10.1007/978-1-4471-3708-5

[19] Thomas, L., Borchers, D., Rexstad, E., Buckland, S., Bravington, M., Wood, S., Hedley, S., Gordari, J., Gillespie, D., Matthews, J. and Peel, D. (2008) Development of New Methods and Software for Distance Sampling Surveys of Cetacean Populations. https://www.researchgate.net/publication/235205668_Development_of_New_Meth ods_and_Software_for_Distance_Sampling_Surveys_of_Cetacean_Populations/stats \#fullTextFileContent

[20] Borchers, D.L. and Burnham, K.P. (2004) General Formulation for Distance Sampling. In: Buckland, S.T., Anderson, D.R., Burnham, K.P., Laake, J.L., Borchers, D.L. and Thomas, L., Eds., Advanced Distance Sampling, Oxford University Press, Oxford, 6-30. 
[21] Gibbons, B.H. and Gibbons, I.R. (1972) Flagellar Movement and Adenosine Triphosphatase Activity in Sea Urchin Sperm Extracted with Triton X-100. Journal of Cell Biology, 54, 79-97. https://doi.org/10.1083/jcb.54.1.75

[22] Laake, J.L., Buckland, S.T., Anderson, D.R. and Burnham, K.P. (2020) Distance User's Guide (Version 2.2).

http://distancesampling.org/Distance/old-versions/downloads/guide.pdf

[23] Oedekoven, C.S., Buckland, S.T., Mackenzie, M.L., Evans, K.O. and Burger, L.W. (2013) Improving Distance Sampling: Accounting for Covariates and Non-Independence between Sampled Sites. Journal of Applied Ecology, 50, 786-793. https://doi.org/10.1111/1365-2664.12065

[24] Oedekoven, C.S., Buckland, S.T., Mackenzie, M.L., King, R., Evans, K.O. and Burger, L.W. (2014) Bayesian Methods for Hierarchical Distance Sampling Models. Journal of Agricultural, Biological, and Environmental Statistics, 19, 219-239. https://doi.org/10.1007/s13253-014-0167-0

[25] UNEP CMS (2008) West Africa Aquatic Mammals-Ghana. https://www.cms.int/en/country/ghana

[26] Diallo, M., Djiba, A., Jallow, A.O., Ndiaye, E., Samba Ould Billal, A.O., Bamy, I.L., Van Waerebeek, K., Barnett, L., Camara, A. and Cham, A. (2004) Distribution, Status and Biology of the Atlantic Humpback Dolphin Sousa teuszii (Kükenthal, 1892). Aquatic Mammals, 30, 56-83.

[27] UNEP CMS (2001) National Report of Ghana (COP10). Convention on the Conservation of Migratory Species of Wild Animals. https://www.cms.int/en/document/national-report-ghana-cop10

[28] Djiba, A., Bamy, I.L., Samba Bilal, A. and Van Waerebeek, K. (2015) Biodiversity of Cetaceans in Coastal Waters of Northwest Africa: New Insights through Platform-of-Opportunity Visual Surveying in 2011-2013. In: Valdés, L. and DénizGonzález, I., Eds., Oceanographic and Biological features in the Canary Current Large Marine Ecosystem, IOC-UNESCO, Paris.

https://www.researchgate.net/publication/285507686_Biodiversity_of_cetaceans_in _coastal_waters_of_Northwest_Africa_new_insights_through_platform-of-opportu nity_visual_surveying_in_2011-2013

[29] Ofori-Danson, P.K., Van Waerebeek, K. and Debrah, S. (2003) A Survey for the Conservation of Dolphins in Ghanaian Coastal Waters. Journal of the Ghana Science Association, 5, 45-54.

[30] Environmental Resource Management (ERM), ESL Consulting and SRC Consulting Ltd./Tullow Ghana Ltd. (2014) Tweneboa, Enyenra, Ntomme (TEN) Project, Ghana: Final Environmental Impact Statement.

https://www.tullowoil.com/application/files/6515/8490/3977/ten-project-environme ntal-impact-statement-volume-2.pdf

[31] ESL Consulting/Eni S.p.A (2015) ESHIA for Ghana OCTP BLOCK Phase 2-World Bank Document.

https://documents1.worldbank.org/curated/en/817641467997610071/pdf/E4834-v2EA-P152670-PUBLIC-Disclosed-9-21-2015-Box393209B.pdf

[32] Leatherwood, S. and Reeves, R.R. (1983) The Sierra Club Handbook of Whales and Dolphins. Sierra Club Books, San Francisco, 302 p.

[33] Di Iorio, L. and Clark C. (2010) Exposure to Seismic Survey Alters Blue Whale Acoustic Communication. Biology Letters, 6, 51-54. https://doi.org/10.1098/rsbl.2009.0651 